\title{
Structure of the Jovian Stratosphere at the Galileo Probe Entry Site
}

\author{
Roger V. Yelle and Caitlin A. Griffith \\ Physics and Astronomy Department, Northern Arizona University, Flagstaff, Arizona 86011 \\ E-mail: yelle@physics.nau.edu \\ and \\ Leslie A. Young \\ Southwest Research Institute, 1050 Walnut Street, Boulder, Colorado 80302
}

Received August 20, 1998; revised April 4, 2001; Posted online June 27, 2001

The structure of the J ovian stratosphere at the Galileo probe entry site is investigated through calculations of radiative heating rates based on measurements of the temperature profile, composition, and aerosol distribution. F rom analysis of mid-I R observations of J upiter, we determine a $\mathrm{C}_{2} \mathrm{H}_{2}$ mole fraction of 1.1- $4.3 \times 10^{-6}$ at $0.01 \mathrm{mbar}$, and a $\mathrm{C}_{2} \mathrm{H}_{6}$ mole fraction of 2.8-6.5 $\times 10^{-6}$ at 0.410 mbar. The derived distributions imply that $\mathrm{C}_{2} \mathrm{H}_{6}$ and $\mathrm{C}_{2} \mathrm{H}_{2}$ are the most important coolants in the J ovian stratosphere from 0.004 to $10 \mathrm{mbar}$, and that the stratosphere is close to radiative equilibrium. In J upiter's stratosphere, as in the stratosphere of the E arth, photochemical species play an essential role in the energy balance. (C) 2001 A cademic Press

Key Words: J upiter; G alileo; stratosphere.

\section{INTRODUCTION}

Jupiter has a well-developed stratosphere with a mean temperature near $10 \mathrm{mbar}$, approximately $50 \mathrm{~K}$ higher than that at the tropopause. This stratospheric temperature shows remarkably little variation with latitude and longitude. Typical equator-topole temperature differences are $2 \mathrm{~K}$ or less (Orton et al. 1991), although there are some localized auroral phenomena that exhibit larger variations. It is tempting to conclude that energy in the jovian stratosphere is efficiently redistributed by dynamics, perhaps driven by a net radiative imbalance. Yet, it is also possible that momentum sources propagating upward from the troposphere dominate stratospheric dynamics on Jupiter. Despite recent contributions, it is fair to say that the relative roles played by radiation and dynamics, and how these interact with composition and chemistry to determine stratospheric structure, are not well determined. A critical factor in all stratospheric investigations is local radiative balance. It is this subject that concerns us here.

The temperature profile in the jovian stratosphere has been studied through observations of emissions from the $v_{4}$ band of
$\mathrm{CH}_{4}$ (Gillet et al. 1969, Orton et al. 1991), stellar occultation experiments (Ververka et al. 1974, Hubbard et al. 1972, 1995), and spacecraft radio occultations experiments (Lindal et al. 1981). More recently, the Atmospheric Structure Instrument (ASI) on the Galileo probe (Sieff et al. 1997, 1998) determined the temperature profile in the jovian stratosphere through analysis of the probe deceleration as it passed through the atmosphere. These in situ results have a higher fidelity than previous determinations of the temperature profile because they are free of the assumptions that accompany interpretation of any remote sensing measurement. In addition, numerous UV and IR observations of Jupiter have been conducted in recent years, in connection with the SL9 impacts and in support of the Galileo mission. These observations constrain the gaseous and aerosol abundances in the jovian stratosphere. Thus, conditions are propitious for a new and in-depth investigation of stratospheric radiation balance on Jupiter.

We examine the energy balance of the stratosphere at the probe entry site by calculating heating rates using the latest $\mathrm{CH}_{4}$ absorption coefficients and cooling rates and considering realistic altitude distributions of $\mathrm{C}_{2} \mathrm{H}_{2}$ and $\mathrm{C}_{2} \mathrm{H}_{6}$ to calculate heating rates. To determine the altitude distributions of $\mathrm{C}_{2} \mathrm{H}_{2}$ and $\mathrm{C}_{2} \mathrm{H}_{6}$, we use mid-IR spectra of equatorial regions in addition to results from previous analyses of mid-IR and UV observations. Comparison of the net heating and cooling rates demonstrates that the jovian stratosphere is close to radiative equilibrium. Or, more precisely, the departures from radiative equilibrium appear to be smaller than the uncertainty in the calculated rates. We find that $\mathrm{C}_{2} \mathrm{H}_{2}$ and $\mathrm{C}_{2} \mathrm{H}_{6}$ are the primary coolants in the stratosphere with $\mathrm{C}_{2} \mathrm{H}_{6}$ dominating at most pressures. The thermal balance and photochemistry of the stratosphere are closely coupled. Latitudinal gradients in the $\mathrm{C}_{2} \mathrm{H}_{2}$ and $\mathrm{C}_{2} \mathrm{H}_{6}$ densities may cause radiative forcing of wind systems that will in turn redistribute $\mathrm{C}_{2} \mathrm{H}_{2}$ and $\mathrm{C}_{2} \mathrm{H}_{6}$. Knowledge of composition, aerosol distribution, and temperature are necessary to develop a complete understanding of the jovian stratosphere. 


\section{PREVIOUS RADIATIVE EQUILIBRIUM MODELS}

Cess and Khetan (1973) and Wallace et al. (1974) conducted the first successful radiative equilibrium calculations of the thermal profile in the jovian stratosphere. The thorough study by Wallace et al. (1974) succeeds in identifying the near-IR $\mathrm{CH}_{4}$ bands as the main source of heating in the stratosphere. Models including these bands alone and cooling through the $v_{4}$ band of $\mathrm{CH}_{4}$ matched the measurements of the stratospheric temperature available at that time. Wallace et al. (1974) did not include radiative cooling by $\mathrm{C}_{2} \mathrm{H}_{2}$ and $\mathrm{C}_{2} \mathrm{H}_{6}$ in their calculations but estimated that significant amounts of these molecules could cool the upper stratosphere by tens of Kelvins.

Cess and Chen (1975) improved the models of Cess and Khetan (1973) to include cooling by $\mathrm{C}_{2} \mathrm{H}_{2}$ and $\mathrm{C}_{2} \mathrm{H}_{6}$. Using constant mole fractions of $1 \times 10^{-5}$ and $5 \times 10^{-7}$ respectively, Cess and Chen (1975) found that $\mathrm{C}_{2} \mathrm{H}_{2}$ and $\mathrm{C}_{2} \mathrm{H}_{6}$ cooled the stratosphere by $20 \mathrm{~K}$. This caused the models to be cooler than temperatures inferred from observations. In order to bring the models back into agreement with the observations, Cess and Chen (1975) hypothesized the presence of significant aerosol heating. Stratospheric aerosols had previously been postulated to explain the low UV albedo of Jupiter (Axel 1972). However, the aerosol heating in these calculations was not deduced from observations but was parameterized and adjusted to produce agreement between observed and calculated temperature profiles.

Appleby and Hogan (1984) and Appleby (1990) continued studies of Jupiter's thermal structure, motivated partly by the availability of Voyager measurements. Following Cess and Chen (1975), Appleby and Hogan (1984) included aerosol heating in a parameterized fashion and found that the aerosols must absorb $3.8 \%$ of the total solar flux in order to bring the models into agreement with temperatures inferred from the Voyager radio occultation experiment. The difference between Appleby and Hogan's aerosol model and their dust-free model is $10 \mathrm{~K} . \mathrm{C}_{2} \mathrm{H}_{2}$ and $\mathrm{C}_{2} \mathrm{H}_{6}$ were included in these models using the formalism developed by Cess and Chen (1975). Constant mixing ratios were assumed with values of $10^{-5}$ and $5 \times 10^{-7}$ for $\mathrm{C}_{2} \mathrm{H}_{6}$ and $\mathrm{C}_{2} \mathrm{H}_{2}$. The relative importance of cooling by $\mathrm{CH}_{4}, \mathrm{C}_{2} \mathrm{H}_{2}$ and $\mathrm{C}_{2} \mathrm{H}_{6}$ was not discussed.

More recent work on the thermal structure of the jovian stratosphere has emphasized the role of dynamics. Voyager and ground-based observations indicate that the temperature of the stratosphere is surprisingly uniform with latitude, implying efficient meridional redistribution of heat (Conrath et al. 1990, Orton et al. 1991). Conrath et al. (1990) utilized a model including radiation and friction to study the dynamics of outer planet stratospheres. These authors found that the lower stratosphere is forced primarily by the prevailing winds in the upper troposphere. Radiative forcing becomes important in the upper stratosphere causing a Hadley-cell circulation pattern with upwelling at low latitudes and subsidence at high latitudes, driven by the excess solar energy deposited in equa- torial regions. Conrath et al. (1990) did not consider aerosol heating.

West et al. (1992) studied the radiative and dynamical structure of the jovian stratosphere using a Transformed Eulerian Mean model to infer diabatic circulation patterns and eddy forcing from observed temperatures and calculations of net radiative heating rates. These authors utilized improved band parameters to calculate energy deposition in $\mathrm{CH}_{4}$ and paid particular attention to aerosols. Observations from IUE and Voyager were used to determine the aerosol distribution as a function of latitude. Cooling from $\mathrm{C}_{2} \mathrm{H}_{2}$ and $\mathrm{C}_{2} \mathrm{H}_{6}$ emissions was included but the $\mathrm{C}_{2} \mathrm{H}_{2}$ and $\mathrm{C}_{2} \mathrm{H}_{6}$ distributions were assumed to be constant with latitude and altitude. West et al. (1992) found that the preponderance of aerosols at high latitudes forced a circulation pattern opposite to that calculated by Conrath et al. (1990) with subsidence in equatorial regions. The results from West et al. (1992) were used by Friedson et al. (1999) to show that the meridional mixing rate of aerosols created in the SL9 collisions was consistent with horizontal eddy mixing derived from the divergence of the Eliasen-Palm flux.

Moreno and Sedano (1997) performed dynamical calculations similar to those of West et al. (1992) but utilized an aerosol distribution based on analysis of multi-wavelength HST images of Jupiter. These data provide higher spatial resolution than possible with the IUE and Voyager data and the aerosol distribution derived by Moreno and Sedano (1997) has fewer aerosols and therefore less heating than that of West et al. (1992) at high northern latitudes. The treatment of gaseous opacities was similar in Moreno and Sedano (1997) and West et al. (1992), with the exception that the former authors included radiative cooling by $\mathrm{NH}_{3}$, which was neglected in earlier studies. Moreno and Sedeno (1997) followed earlier authors in assuming the distributions of $\mathrm{C}_{2} \mathrm{H}_{2}$ and $\mathrm{C}_{2} \mathrm{H}_{6}$ to be uniform with latitude and altitude. Moreno and Sedano (1997) found good agreement with West et al. (1992) at pressures greater than 100 mbar but a significantly different circulation pattern at lower pressures, as a consequence of the different aerosol heating pattern.

The dynamical studies mentioned above have demonstrated the important role of latitudinal variations in aerosol heating in driving dynamics. However, all studies to date have made the questionable assumption that the mole fractions of $\mathrm{C}_{2} \mathrm{H}_{2}$ and $\mathrm{C}_{2} \mathrm{H}_{6}$ are constant with latitude and most have incorrectly assumed that they are constant with altitude. Our results show that latitudinal variations in $\mathrm{C}_{2} \mathrm{H}_{6}$ could be more important than aerosol variations in driving stratospheric dynamics.

\section{OBSE RVATIONAL CONSTRAINTS}

The radiative terms in the energy balance of Jupiter's stratosphere depend on the abundance of gaseous constituents, the abundance, size distribution, and optical properties of aerosols, and the temperature profile. We discuss all of these quantities, starting with the temperature profile. 


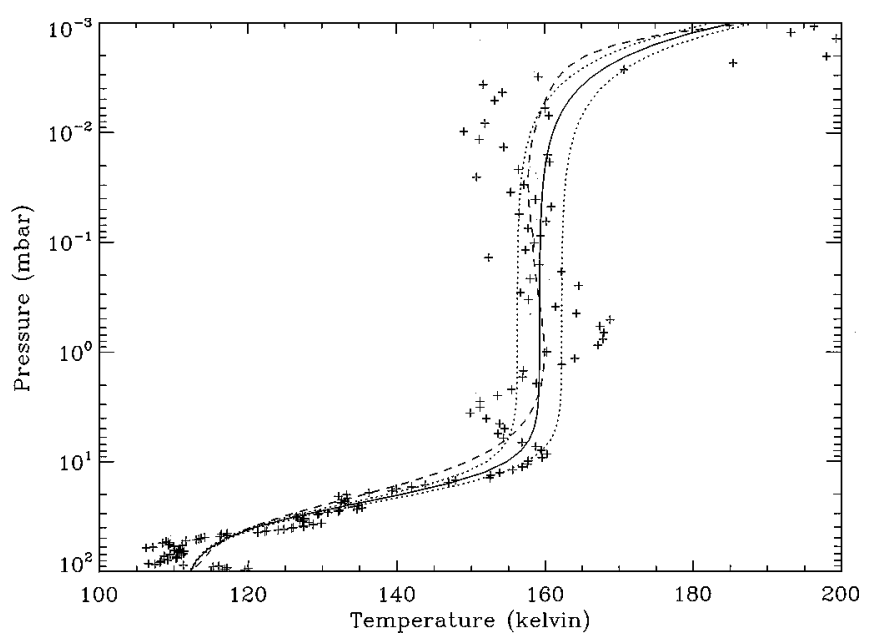

FIG. 1. The temperature profile inferred from the Galileo ASI experiment and three analytic approximations to the mean thermal structure. The solid line is the best-fit least-squares model given in Eq. (1). The dotted lines are models with $T_{1}$ altered by $\pm 3 \mathrm{~K}$ from the best fit value of $160 \mathrm{~K}$. The dashed line is a radiative equilibrium model.

\subsection{Temperature Profile}

Figure 1 shows the temperature profile of the Jovian stratosphere derived from ASI measurements of the acceleration the Galileo probe (Sieff et al. 1998). These data were obtained at a latitude of $6^{\circ} \mathrm{N}$. The mean temperature in the stratosphere is $160 \mathrm{~K}$ and the temperature at the tropopause is $110 \mathrm{~K}$. The temperature rise to the thermosphere begins at about 0.001 mbar. Oscillations in the measured temperature about the mean value are significantly larger than the uncertainty in the ASI measurements. The temperature perturbations have been interpreted as the manifestation of waves in the atmosphere (Sieff et al. 1997, 1998, Young et al. 1997). We are interested in the mean state of the atmosphere and have therefore fit the ASI temperature profile with a smooth function of the form

$$
T(p)=T_{0}+\frac{T_{1}-T_{0}}{1+\left(p / p_{1}\right)^{\alpha_{1}}}+\frac{T_{2}-T_{1}}{1+\left(p / p_{2}\right)^{\alpha_{2}}} .
$$

The constants determined by the fit have the following values: $T_{0}=111 \mathrm{~K}, T_{1}=159.7 \mathrm{~K}, p_{1}=24.1 \mathrm{mbar}, \alpha_{1}=2.45$, $T_{2}=900 \mathrm{~K}, p_{2}=6.13 \times 10^{-5} \mathrm{mbar}$, and $\alpha_{2}=1.21$. We use the fitted profile in the analysis of observations of $\mathrm{C}_{2} \mathrm{H}_{2}$ and $\mathrm{C}_{2} \mathrm{H}_{6}$ emissions and in the calculation of radiative heating and cooling rates to be discussed below. Also shown in Fig. 1 are analytic models with $T_{1}$ differing by $3 \mathrm{~K}$ from the best fit value. These curves are used to evaluate the uncertainty in the mole fractions and cooling rates.

Horizontal variations in the stratospheric temperature have been addressed by Orton et al. (1991), who published maps of brightness temperature in the $v_{4}$ band of $\mathrm{CH}_{4}$. These observations revealed that the zonal mean structure alternates between states of warm subtropical $\left(\sim 14^{\circ}\right)$ and cool equatorial regions to cool subtropical and warm equatorial regions, with a period of about four years. The brightness temperature variations from equator to $\sim 14^{\circ}$ have a magnitude of 1-2 K. Leovy et al. (1991) and Friedson (1999) have interpreted these variations as an oscillation in the jovian stratosphere similar to the quasi-biennial oscillation (QBO) in the terrestrial stratosphere. Friedson (1999) also points out that the variations in the physical temperature of the stratosphere are larger than the variation in brightness temperature observed by Orton et al. (1991) because the observations sample a broad pressure region and the temperature resulting from the QBO-like oscillation is confined to a relatively narrow pressure region. If Friedson's interpretation is correct then some of the apparent perturbations in the ASI profile are long-lived and should be considered in our analysis. However, Friedson calculates temperature variations from $7.2^{\circ} \mathrm{N}$ to $14^{\circ} \mathrm{S}$ of about $3 \mathrm{~K}$ and the possibility of that the wave-like features are long-lived is addressed by considering the range of temperature profiles discussed above.

\subsection{The $\mathrm{CH}_{4}$ and He Distributions}

Of the numerous species detected in the atmosphere of Jupiter, $\mathrm{H}_{2}, \mathrm{CH}_{4}, \mathrm{C}_{2} \mathrm{H}_{2}$, and $\mathrm{C}_{2} \mathrm{H}_{6}$ are important to the energy balance in the stratosphere. Measurements of the abundances of the thermally active species in the equatorial stratosphere are summarized in Table I.

The Gas Chromatograph Mass Spectrometer Experiment (GCMS) on the Galileo probe measured the $\mathrm{He}$ and $\mathrm{CH}_{4}$ abundances in the jovian troposphere. Helium is relatively abundant with a mole fraction of $13.6 \%$, but is inert and influences the atmosphere primarily by altering the mean molecular weight. A $\mathrm{CH}_{4}$ mole fraction of $0.2 \%$ was measured in the troposphere. Both $\mathrm{He}$ and $\mathrm{CH}_{4}$ should have constant mole fractions at pressures greater than $\sim 0.01$ mbar. At lower pressures their abundance decreases because of diffusive separation. $\mathrm{The}^{\mathrm{CH}} \mathrm{H}_{4}$ profile near the homopause has been characterized by Yelle et al. (1996) through analysis of the Voyager 2 Ultraviolet Spectrometer (UVS) occultation of $\alpha$ Leo.

In the appendix we derive the following formula for the diffusive equilibrium distribution of a minor species,

$$
f_{i}(p)=f_{i 0}\left(1+r\left(p_{0} / p\right)^{1-\gamma}\right)^{\frac{1-m_{i} / m_{0}}{1-\gamma}},
$$

where $f_{i}(p)$ is the mole fraction of the ith minor constituent and $f_{i 0}(p)$ is its value deep in the atmosphere. The quantity $r$ is the ratio of the eddy diffusion and molecular diffusion coefficients at reference pressure $p_{0} ; m_{i}$ is the molecular mass of $\mathrm{CH}_{4}$; and $m_{0}$ the molecular mass of the background atmosphere. The eddy diffusion coefficient is assumed to have the same temperature dependence as the molecular diffusion coefficient and to vary with pressure as

$$
K(p)=K_{0}\left(p_{0} / p\right)^{\gamma}
$$

Equation (2) differs from previous published solutions because 
TABLE I

Measurements of Stratospheric C omposition on J upiter

\begin{tabular}{|c|c|c|c|c|c|}
\hline Species & Mole Fraction & $\begin{array}{c}\text { Pressure }^{a} \\
\quad(\mathrm{mbar})\end{array}$ & $\begin{array}{l}\text { Technique/ } \\
\text { Instrument }^{b}\end{array}$ & $\begin{array}{l}\text { Assumed } \\
\text { Temperature }\end{array}$ & Reference \\
\hline $\mathrm{H}_{2}$ & 0.87 & $>100$ & GCMS & - & Niemann et al. (1996) \\
\hline $\mathrm{He}$ & 0.13 & $>100$ & GCMS & - & Niemann et al. (1996) \\
\hline \multirow{2}{*}{$\mathrm{CH}_{4}$} & $1-2 \times 10^{-4}$ & $1-4 \times 10^{-4}$ & UVS & - & Yelle et al. (1996) \\
\hline & $1.9 \times 10^{-3}$ & $>100$ & GCMS & - & Niemann et al. (1996) \\
\hline \multirow[t]{13}{*}{$\mathrm{C}_{2} \mathrm{H}_{2}$} & $1 \times 10^{-7}$ & & IUE & - & Clarke et al. (1982) \\
\hline & $9-11 \times 10^{-8}$ & $5-15(10)$ & IUE & - & Gladstone and Yung (1983) \\
\hline & $2-4 \times 10^{-8}$ & $5-15(10)$ & IUE & - & Wagener et al. (1985) \\
\hline & $7-13 \times 10^{-8}$ & $0.1-4(1.5)$ & IR/FP & $150-170 \mathrm{~K}$ & Noll et al. (1986) \\
\hline & $3.6 \times 10^{-8}$ & $5-15(10)$ & IUE & - & McGrath et al. (1990) \\
\hline & $3.6-4.3 \times 10^{-8}$ & $5-15(10)$ & HUT(1) & - & Morrissey et al. (1995) \\
\hline & $2.6-3.1 \times 10^{-8}$ & $5-15(10)$ & HUT(2) & - & \\
\hline & $1.8-2.8 \times 10^{-8}$ & 8 & CELESTE & $140 \mathrm{~K}$ & Sada et al. (1998) \\
\hline & $1-3 \times 10^{-8}$ & $20-60$ & FOS & - & Bétremieux and Yelle (2000) \\
\hline & $2-5 \times 10^{-8}$ & 10 & FOS & - & \\
\hline & $8.3-10 \times 10^{-7}$ & 0.3 & ISO & $165 \mathrm{~K}$ & Fouchet et al. (2000) \\
\hline & $1.0-1.3 \times 10^{-7}$ & 4 & ISO & $165 \mathrm{~K}$ & Fouchet et al. (2000) \\
\hline & $1.1-4.3 \times 10^{-6}$ & $0.01^{c}$ & Irshell & $160 \mathrm{~K}$ & This work \\
\hline \multirow{11}{*}{$\mathrm{C}_{2} \mathrm{H}_{6}$} & $4-7 \times 10^{-6}$ & $0.1-4(1.5)$ & IR/FP & $150-170 \mathrm{~K}$ & Noll et al. (1986) \\
\hline & $2.2-3.4 \times 10^{-6}$ & $0.7-30(5)$ & IR/Heterodyne & $150-170 \mathrm{~K}$ & Kostiuk et al. (1987) \\
\hline & $1-12 \times 10^{-6}$ & $1-20(4)$ & IUE & - & Gladstone and Yung (1983) \\
\hline & $1-4 \times 10^{-6}$ & $1-20(4)$ & IUE & - & Wagener et al. (1985) \\
\hline & $1.7 \times 10^{-6}$ & $1-20(4)$ & IUE & - & McGrath et al. (1990) \\
\hline & $2.1-3.9 \times 10^{-6}$ & $1-20(4)$ & HUT(1) & - & Morrissey et al. (1995) \\
\hline & $2.4-3.8 \times 10^{-6}$ & $1-20(4)$ & HUT(2) & - & Morrissey et al. (1995) \\
\hline & $2.6-5.8 \times 10^{-6}$ & 5 & CELESTE & $145 \mathrm{~K}$ & Sada et al. (1998) \\
\hline & $0.8-1.2 \times 10^{-5}$ & 1 & ISO & $165 \mathrm{~K}$ & Fouchet et al. (2000) \\
\hline & $2.0-3.1 \times 10^{-6}$ & 10 & ISO & $152 \mathrm{~K}$ & Fouchet et al. (2000) \\
\hline & $2.8-6.5 \times 10^{-6}$ & $0.4-10(5)$ & Irshell & $160 \mathrm{~K}$ & This work \\
\hline
\end{tabular}

${ }^{a}$ The range of pressures indicates the width of the contribution function; the value in parentheses, the location of the peak. Mole fractions are reported at the peak contribution function pressure. The mole fractions of $\mathrm{H}_{2}, \mathrm{He}$, and $\mathrm{CH}_{4}$ are expected to be constant at pressures greater than $\sim 10 \mu$ bar.

${ }^{b}$ GCMS, Galileo Probe Gas Chromatograph and Mass Spectrometer experiment; UVS, Voyager Ultraviolet Spectrometer occultation experiment; IUE, The International Ultraviolet Explorer; IR/FP Ground-based IR observations with a Fabry-Perot Spectrometer with resolving power of 7100; HUT, the Hopkins Ultraviolet Telescope-(1) and (2) refer to the first and second flight; FOS, the Faint Object Spectrograph on HST; ISO, the Infrared Spectroscopy Observer; Irshell, The University of Texas mid-IR spectrometer; IR/Heterodyne, IR observations with a Heterodyne Spectrometer at a resolving power of $10^{6}$.

${ }^{c}$ Derivation of this value assumes $\mathrm{C}_{2} \mathrm{H}_{2}$ mole fractions of $8.3-10 \times 10^{-7}$ and $2-4 \times 10^{-8}$ at 0.3 and 10 mbar.

it has no explicit dependence on temperature; as a consequence, it is particularly useful for thermal balance calculations. This formula neglects photolysis, but this is not a major concern because the diffusion time constant is more than a factor of two less than the photolysis time constant at all levels. Moreover, the uncertainty in the rate of diffusive separation is larger than the effect of photolysis, so nothing is gained by including chemistry until the altitude profile of $\mathrm{CH}_{4}$ is better constrained.

Figure 2 shows a $\mathrm{CH}_{4}$ distribution based on Eq. (2), the Voyager UVS results and the GCMS measurement along with a $\mathrm{CH}_{4}$ profile presented in Gladstone et al. (1996) for the north equatorial belt. The Gladstone et al. (1996) model has been translated to the smoothed ASI temperature profile by assuming that mole fractions at a given pressure remain constant despite the different temperature profiles used. The onset of diffusive equilibrium occurs at a deeper pressure in the Gladstone et al. (1996) model than indicated by the UVS determination of the $\mathrm{CH}_{4}$ density (Yelle et al. 1996). Thus, although the Gladstone et al. (1996) calculations are far more sophisticated, we adopt the analytic models for our thermal structure studies. The diffusive equilibrium model is also used to model the He mole fraction. Molecular diffusion coefficients for $\mathrm{CH}_{4}$ and $\mathrm{He}$ are taken from Mason and Marrero (1970).

\subsection{Previous Determinations of $\mathrm{C}_{2} \mathrm{H}_{2}$ and $\mathrm{C}_{2} \mathrm{H}_{6}$ Mole Fractions}

UV observations have been used to infer the distributions of $\mathrm{C}_{2} \mathrm{H}_{2}$ and $\mathrm{C}_{2} \mathrm{H}_{6}$ in the jovian stratosphere for nearly 20 years. Gladstone and Yung (1983) analyzed the International Ultraviolet Explorer (IUE) observations of Jupiter from Clarke et al. (1982) at wavelengths less than $174 \mathrm{~nm}$ and, assuming a homogeneous atmosphere, determined $\mathrm{C}_{2} \mathrm{H}_{2}$ and $\mathrm{C}_{2} \mathrm{H}_{6}$ mole fractions of $10^{-7}$ and $7 \times 10^{-6}$, respectively. Wagener et al. (1985) also analyzed IUE observations of Jupiter but extended the analysis to the $145-315 \mathrm{~nm}$ region and determined mole fractions for $\mathrm{C}_{2} \mathrm{H}_{2}$ of $3 \pm 1 \times 10^{-8}$, assumed to be constant in the stratosphere. Wagener et al. (1985) argue that the difference between 


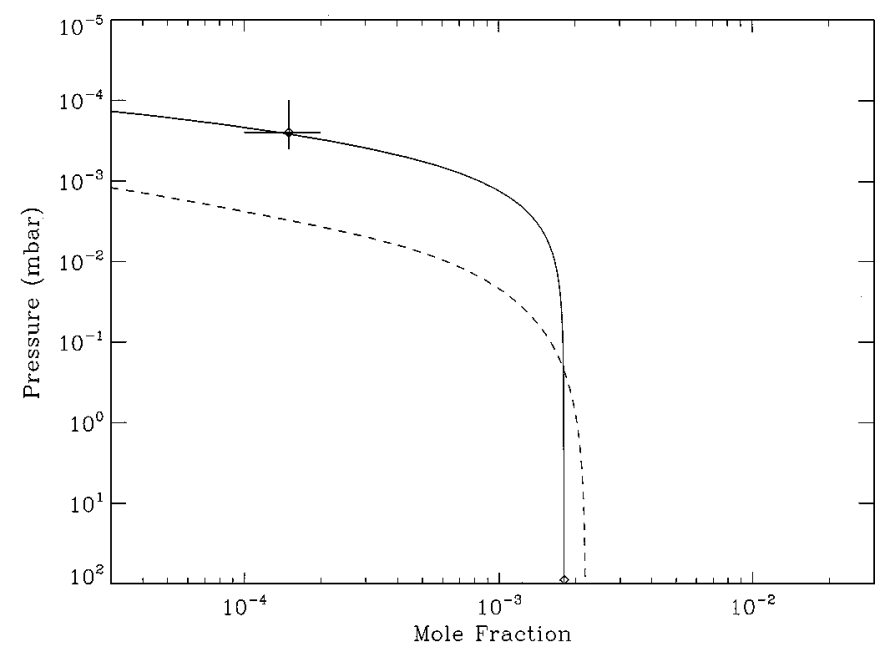

FIG. 2. The distribution of $\mathrm{CH}_{4}$. The solid line is constrained to fit the inferred mole fractions of Niemann et al. (1996) and Yelle et al. (1996) from Table I and is the model used in this investigation. The dashed line is the NEB model from Gladstone et al. (1996) and provides a poor fit to the Yelle et al. (1996) results.

their results and Gladstone and Yung (1983) is due to the restricted wavelength range in the latter study. This is probably correct, but it means that the Gladstone and Yung (1983) results pertain to higher altitudes than the Wagener et al. (1985) results, not that the Gladstone and Yung (1983) results should be supplanted by the Wagener et al. (1985) results, as those authors suggest. Taken together the results from Gladstone and Yung (1983) and Wagener et al. (1985) indicate that the $\mathrm{C}_{2} \mathrm{H}_{2}$ mole fraction increases strongly with decreasing pressure in the jovian atmosphere.

Gladstone and Yung (1983) also provided a useful analytic approximation for the relationship between reflectivity and single

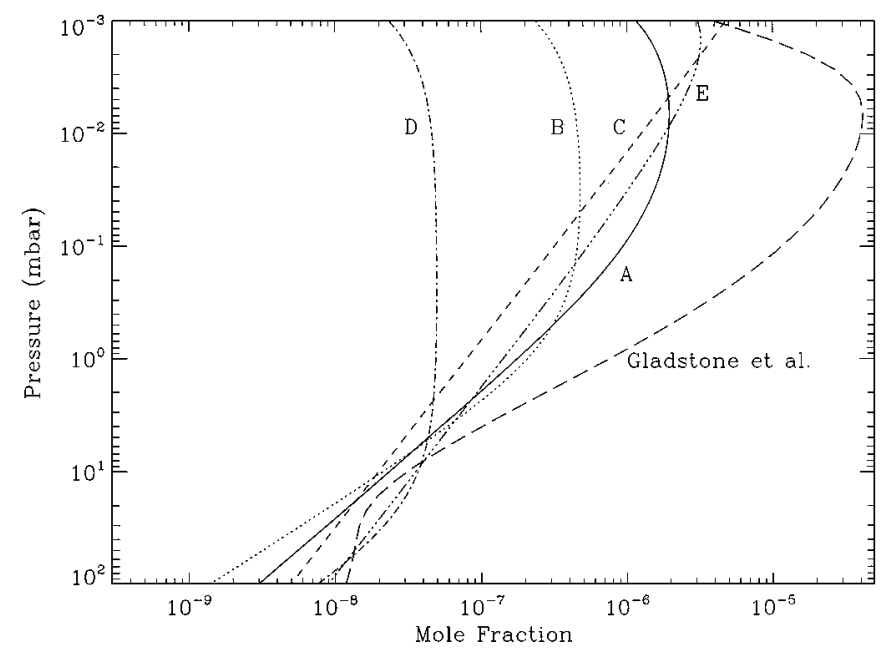

FIG. 3. Models for the $\mathrm{C}_{2} \mathrm{H}_{2}$ distribution that fit the Irshell observations of the $v_{5}$ band. Parameters describing the models are summarized in Table II. The NEB model from Gladstone et al. (1996) is also shown. scattering albedo in a homogeneous atmosphere from which the molecular abundances can be obtained. McGrath et al. (1990) in an analysis of later IUE data and Morrissey et al. (1995) in an analysis of data from the Hopkins Ultraviolet Telescope (HUT) used this formula. The former authors determined $\mathrm{C}_{2} \mathrm{H}_{2}$ and $\mathrm{C}_{2} \mathrm{H}_{6}$ mole fractions of $3.6 \times 10^{-8}$ and $1.7 \times 10^{-6}$, while the latter authors determined $\mathrm{C}_{2} \mathrm{H}_{2}$ and $\mathrm{C}_{2} \mathrm{H}_{6}$ mole fractions of 3.6-4.3 $\times 10^{-8}$ and 2.1-3.9 $\times 10^{-6}$ for data acquired during the Astro- 1 mission and 2.6-3.1 $\times 10^{-8}$ and 2.4-3.8 $\times 10^{-6}$ for dat acquired during the Astro- 2 mission. The HUT observations have good signal-to-noise from 145-190 nm making these data particularly useful for retrieval of the $\mathrm{C}_{2} \mathrm{H}_{6}$ abundance. Morrisey et al. (1995) do not discuss the pressure regime investigated by their observations, but because their wavelength range is similar to that of Gladstone and Yung (1983), it is likely that the same pressures are probed.

Bétremieux and Yelle $(1999,2000)$ analyzed observations of Jupiter in the 175-230 nm spectral range made with the Faint Object Spectrograph (FOS) on the Hubble Space Telescope (HST). Their radiative transfer models included Raman scattering and utilized vertically inhomogeneous aerosol layers, clouds, and distributions of absorptive gaseous constituents. Bétremieux and Yelle $(1999,2000)$ found a cloud structure significantly different from that found by Wagener et al. (1985); however, the $\mathrm{C}_{2} \mathrm{H}_{2}$ mole fraction in the 20-60 mbar region was determined to be $1-3 \times 10^{-8}$, consistent with Wagener et al.'s (1985) results. Bétremieux and Yelle $(1999,2000)$ found that the $\mathrm{C}_{2} \mathrm{H}_{2}$ mole fraction increased to $2-5 \times 10^{-8}$ near 10 mbar indicating an increase of mole fraction with decreasing pressure, as suggested above. The relatively high low wavelength limit of valid FOS data prevented probing any higher into the stratosphere or determining the $\mathrm{C}_{2} \mathrm{H}_{6}$ mole fraction. Edgington et al. (1998) also analyzed the HST/FOS spectra of Jupiter; however, the $\mathrm{C}_{2} \mathrm{H}_{2}$ distribution is not discussed in depth in this paper and the fit to

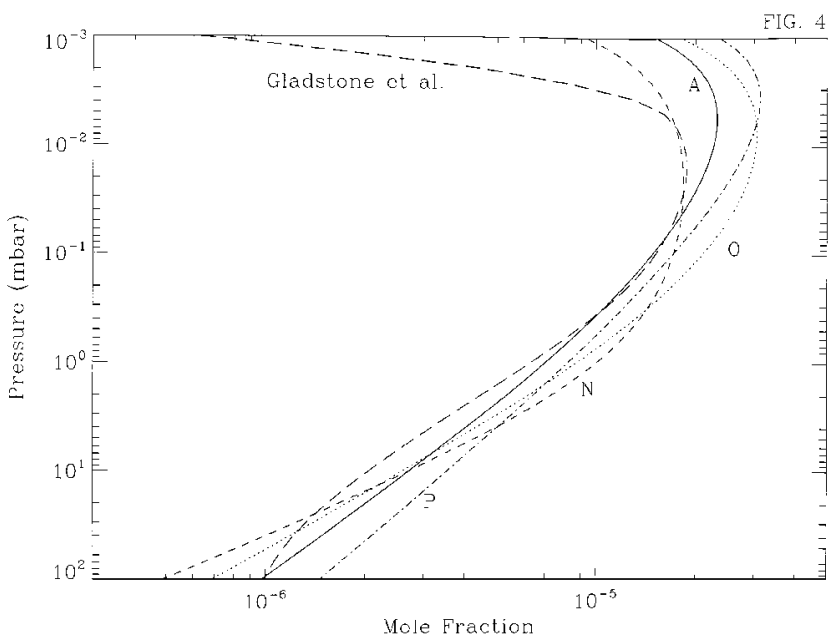

FIG . 4. Models for the $\mathrm{C}_{2} \mathrm{H}_{6}$ distribution that fit the Irshell observations of the $\nu_{9}$ band. Parameters describing the models are summarized in Table II. The NEB model from Gladstone et al. (1996) is also shown. 
the $\mathrm{C}_{2} \mathrm{H}_{2}$ band depths is poor in the $175-200 \mathrm{~nm}$ region (see their Figs. 4 and 5).

The first observation of $\mathrm{C}_{2} \mathrm{H}_{2}$ and $\mathrm{C}_{2} \mathrm{H}_{6}$ mid-IR emissions from Jupiter is due to Ridgway (1974), followed quickly by Combes et al. (1974). Subsequent observations were published by Orton and Aumman (1977), Tokunaga et al. (1976, 1979, Encrenaz et al. (1978), Noll et al. (1986), and Kostiuk et al. (1987). More recently, Sada et al. (1998) analyzed mid-IR observations of Jupiter obtained in late 1994 and early 1995, shortly after the collision of comet P/Shoemaker-Levy 9. Observations were made with the Celeste spectrometer with the slit aligned along the central meridian. The data analyzed extended from $58^{\circ} \mathrm{S}$ to $58^{\circ}$ N. Sada et al. (1998) determined stratospheric temperatures through analysis of $\mathrm{CH}_{4}$ emissions and derived values $\sim 10 \mathrm{~K}$ warmer than those measured by Galileo. The authors suggest that the discrepancy is evidence for horizontal variations in the stratospheric temperature, but this suggestion is inconsistent with the magnitude of stratospheric temperature variations observed by Orton et al. (1991). Sada et al. (1998) determined $\mathrm{C}_{2} \mathrm{H}_{2}$ and $\mathrm{C}_{2} \mathrm{H}_{6}$ densities by using altitude distributions calculated with photochemical models that were scaled to produce agreement with the observations. They determine mole fractions for $\mathrm{C}_{2} \mathrm{H}_{2}$ and $\mathrm{C}_{2} \mathrm{H}_{6}$ of $2.3 \pm 0.5 \times 10^{-8}$ and $3.9_{-1.3}^{+1.9} \times 10^{-6}$ at 8 and 5 mbar, respectively. These values should be viewed as an average over equatorial and midlatitude regions. If the stratospheric temperature is indeed cooler than found by Sada et al. (1998) then the mole fractions of $\mathrm{C}_{2} \mathrm{H}_{2}$ and $\mathrm{C}_{2} \mathrm{H}_{6}$ would be larger.

Fouchet et al. (2000) derived the abundance of $\mathrm{C}_{2} \mathrm{H}_{2}$ and $\mathrm{C}_{2} \mathrm{H}_{6}$ from analysis of ISO observations of Jupiter. These observations encompassed a region on Jupiter extending from $30^{\circ} \mathrm{S}$ to $30^{\circ} \mathrm{N}$ and $\pm 20^{\circ}$ in longitude about the central meridian. These authors determined the stratospheric temperature from observations of the $\mathrm{CH}_{4}$ emissions and found a profile that was $2 \mathrm{~K}$ cooler than the smoothed ASI profile from 5 to 30 mbar and $4 \mathrm{~K}$ warmer at pressures less than 5 mbar. Fouchet et al. (2000) considered $\mathrm{C}_{2} \mathrm{H}_{2}$ and $\mathrm{C}_{2} \mathrm{H}_{6}$ profiles in which the mole fraction varies as pressure to a constant power. They determined a $\mathrm{C}_{2} \mathrm{H}_{2}$ mole fraction that varies from $8.9_{-0.6}^{+1.1} \times 10^{-7}$ at 0.3 mbar to $1.1_{-0.1}^{+0.2} \times$ $10^{-7}$ at 4 mbar and a $\mathrm{C}_{2} \mathrm{H}_{6}$ mole fraction that varies from $1.0 \pm$ $0.2 \times 10^{-5}$ at 1 mbar to $2.6_{-0.6}^{+0.5} \times 10^{-6}$ at 10 mbar. Fouchet et al. (2000) determine an uncertainty in the mole fractions of $\mathrm{C}_{2} \mathrm{H}_{2}$ and $\mathrm{C}_{2} \mathrm{H}_{6}$ of 20 and $25 \%$ for a temperature uncertainty of $2 \mathrm{~K}$.

The preceding summary reveals that, although there is agreement among most of the determinations of $\mathrm{C}_{2} \mathrm{H}_{2}$ and $\mathrm{C}_{2} \mathrm{H}_{6}$ mole fractions to within a factor of several, it is difficult to use these observations to construct precise altitude distribution models. Several of the observations encompass a large range of latitudes, while it is our intention to concentrate on the equatorial region. In addition, different studies assume different stratospheric temperature profiles and, for the mid-IR measurements, this has a large effect on the derived mole fractions. Similarly, different investigators characterize the altitude distribution of species in different ways, with some adopting constant profiles, others using complex photochemical models, and others (including us) using simple analytic forms. Making sense of these different results is made more difficult by the fact that the spectra are formed over a broad altitude region. Often, it is not clear if discrepant results represent a real difference or a different altitude weighting. For our purposes, it is essential that consistent assumptions are made in the analysis of the hydrocarbon emissions and the radiative balance calculations, and that the uncertainties in these quantities are understood. Therefore, we present a new determination of the $\mathrm{C}_{2} \mathrm{H}_{2}$ and $\mathrm{C}_{2} \mathrm{H}_{6}$ density profiles through analysis of emissions from the equatorial regions obtained using a small aperture and high spectral resolution. The results, presented in Figs. 3 and 4 are described in the next section.

\subsection{Irshell Measurements of $\mathrm{C}_{2} \mathrm{H}_{2}$ and $\mathrm{C}_{2} \mathrm{H}_{6}$}

Spectra of the the $v_{5}$ band of $\mathrm{C}_{2} \mathrm{H}_{2}$ (Fig. 5) and the $v_{9}$ band of $\mathrm{C}_{2} \mathrm{H}_{6}$ (Fig. 6) were recorded at NASA's Infrared Telescope Facility with the Irshell spectrometer (Lacy et al. 1989) in 1995, on May 16 (UT 12:02) and May 18 (UT $13: 24$ ), respectively. These data, selected from observations published by Bézard et al. (1997a), sample a $3 \times 3^{\prime \prime}$ region centered at $2^{\circ} \mathrm{N}$ latitude, for $\mathrm{C}_{2} \mathrm{H}_{2}$ and $21^{\circ} \mathrm{S}$ latitude, for $\mathrm{C}_{2} \mathrm{H}_{6}$, corresponding to jovian air masses of 1.01 and 1.06. The spectra have resolutions of 0.11 $\left(\mathrm{C}_{2} \mathrm{H}_{2}\right)$ and $0.16 \mathrm{~cm}^{-1}\left(\mathrm{C}_{2} \mathrm{H}_{6}\right)$.

The observations are analyzed assuming the temperature profiles discussed in Section 3.1, considering both the best-fit temperature profile and the profiles that differ by $\pm 3 \mathrm{~K}$. We examine this range of thermal profiles to take into account both the observed temperature variations with latitude and possible variations in the vertical structure of the thermal profile. An alternate approach would be to construct thermal profiles based on Friedson's (1999) theory of the stratospheric thermal profile. We choose not to follow this course for several reasons. The arguments of Leovy et al. (1991) and Friedson (1999), though

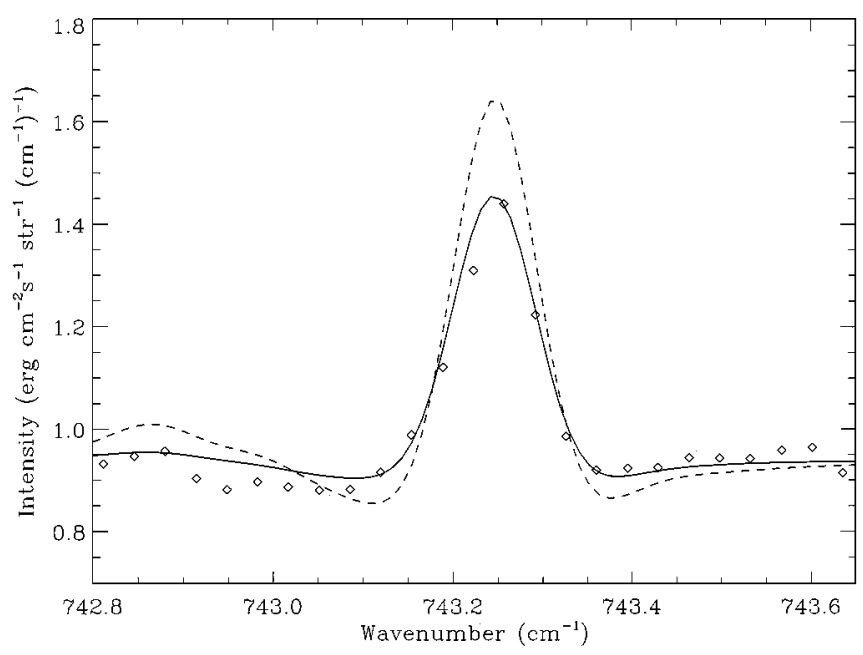

FIG. 5. Irshell observations of $\mathrm{C}_{2} \mathrm{H}_{2}$ and a synthetic spectrum (solid line) based on the smoothed ASI temperature profile and model A. The dashed line is a synthetic spectrum based on the Gladstone et al. (1996) photochemical model. 


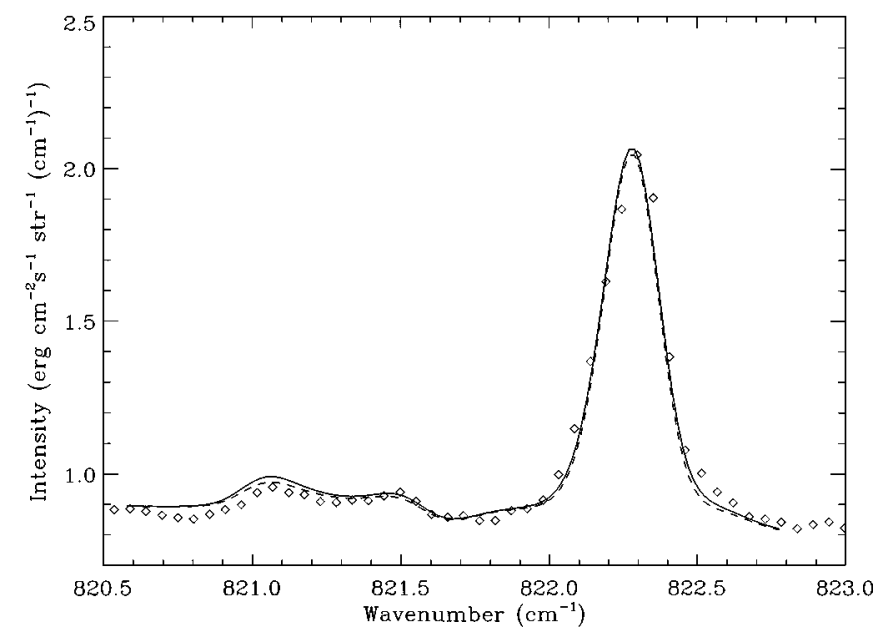

FIG . 6. Irshell observations of $\mathrm{C}_{2} \mathrm{H}_{6}$ and a synthetic spectrum (solid line) based on the smoothed ASI temperature profile and model A. The dashed line is a synthetic spectrum based on the Gladstone et al. (1996) photochemical model, modified at low pressure to be consistent with the eddy diffusion coefficient from Yelle et al. (1996).

compelling, are not conclusive. For example, they are unable to tie the QBO-like oscillation directly to a forcing mechanism, as has been done for the terrestrial stratosphere (Friedson 1999). Therefore, we believe that it is wiser to treat the QBO explanation as a hypothesis, rather than incorporate it directly into our work. Moreover, Friedson's calculations indicate that the largest temperature differences between $6^{\circ} \mathrm{N}$ latitude (the region sampled by ASI measurements) and the $2^{\circ} \mathrm{N}$ and $21^{\circ} \mathrm{S}$ latitude (where the $\mathrm{C}_{2} \mathrm{H}_{2}$ and $\mathrm{C}_{2} \mathrm{H}_{6}$ observations probed) are 7 and $3 \mathrm{~K}$, respec- tively. While the $7 \mathrm{~K}$ difference lies outside our error margin, it also pertains to a narrow pressure region. The more significant coolant, $\mathrm{C}_{2} \mathrm{H}_{6}$, is analyzed with a thermal profile within the theoretically predicted variation at all pressures. The effects of these departures from our assumed smooth profile would not produce distributions of $\mathrm{C}_{2} \mathrm{H}_{2}$, and particularly $\mathrm{C}_{2} \mathrm{H}_{6}$, very different from those derived here.

In order to model the vertical distributions of $\mathrm{C}_{2} \mathrm{H}_{2}$ and $\mathrm{C}_{2} \mathrm{H}_{6}$, we use a function of the form

$$
f=\frac{f_{1} f_{2}}{f_{1}+f_{2}},
$$

where $f_{1}$ has the form given in Eq. (2) with the same exponential factors, but $f_{10}$ is allowed to differ from that for $\mathrm{CH}_{4}$. The function $f_{2}$ is given by

$$
f_{2}(p)=f_{20}\left(p_{0} / p\right)^{\gamma}
$$

Thus, the function $f(p)$ has three free parameters, $f_{10}, f_{20}$, and $\gamma$ that control, respectively, the mole fraction in the upper stratosphere, the mole fraction at the base of the stratosphere, and the slope in the intervening region. This provides enough freedom to match the $\mathrm{C}_{2} \mathrm{H}_{2}$ and $\mathrm{C}_{2} \mathrm{H}_{6}$ observations and to mimic the more complete photochemical calculations. Figures 3 and 4 show a variety of models that fit the Irshell observations. Values for the parameters needed to calculate these distributions are presented in Table II.

Synthetic spectra are computed with radiative transfer calculations that use a line-by-line (LBL) technique to determine absorption coefficients based on line positions, energy levels,

TABLE II

\begin{tabular}{|c|c|c|c|c|c|c|c|}
\hline \multirow[b]{2}{*}{ Model } & \multicolumn{3}{|c|}{$\mathrm{C}_{2} \mathrm{H}_{2}$} & \multicolumn{3}{|c|}{$\mathrm{C}_{2} \mathrm{H}_{6}$} & \multirow{2}{*}{$\begin{array}{l}\text { Temp. } \\
\text { Profile }\end{array}$} \\
\hline & $f_{10}$ & $f_{20}$ & $\gamma$ & $f_{10}$ & $f_{20}$ & $\gamma$ & \\
\hline A & $2.5 \times 10^{-6}$ & $3.0 \times 10^{-9}$ & 0.9 & $2.0 \times 10^{-5}$ & $4.0 \times 10^{-7}$ & 0.80 & med \\
\hline B & $5.0 \times 10^{-7}$ & $1.4 \times 10^{-9}$ & 1.2 & $2.0 \times 10^{-5}$ & $4.0 \times 10^{-7}$ & 0.80 & med \\
\hline $\mathrm{C}$ & $2.0 \times 10^{-4}$ & $3.0 \times 10^{-9}$ & 0.6 & $2.0 \times 10^{-5}$ & $4.0 \times 10^{-7}$ & 0.80 & med \\
\hline $\mathrm{D}$ & $5.0 \times 10^{-8}$ & $9.0 \times 10^{-9}$ & 1.2 & $2.0 \times 10^{-5}$ & $4.0 \times 10^{-7}$ & 0.80 & med \\
\hline $\mathrm{E}$ & $1.0 \times 10^{-5}$ & $9.0 \times 10^{-9}$ & 0.6 & $2.0 \times 10^{-5}$ & $4.0 \times 10^{-7}$ & 0.80 & med \\
\hline $\mathrm{F}$ & $5.0 \times 10^{-6}$ & $1.4 \times 10^{-9}$ & 1.2 & $4.0 \times 10^{-5}$ & $1.2 \times 10^{-6}$ & 0.60 & cold \\
\hline $\mathrm{G}$ & $4.0 \times 10^{-4}$ & $5.0 \times 10^{-9}$ & 0.6 & $4.0 \times 10^{-5}$ & $1.2 \times 10^{-7}$ & 0.60 & cold \\
\hline $\mathrm{H}$ & $2.0 \times 10^{-7}$ & $3.0 \times 10^{-8}$ & 1.2 & $4.0 \times 10^{-5}$ & $1.2 \times 10^{-7}$ & 0.60 & cold \\
\hline I & $2.0 \times 10^{-5}$ & $1.0 \times 10^{-8}$ & 0.6 & $4.0 \times 10^{-5}$ & $1.2 \times 10^{-7}$ & 0.60 & cold \\
\hline $\mathrm{J}$ & $1.0 \times 10^{-7}$ & $1.4 \times 10^{-9}$ & 1.2 & $1.6 \times 10^{-5}$ & $3.0 \times 10^{-7}$ & 0.80 & hot \\
\hline $\mathrm{K}$ & $3.0 \times 10^{-5}$ & $5.0 \times 10^{-9}$ & 0.6 & $1.6 \times 10^{-5}$ & $3.0 \times 10^{-7}$ & 0.80 & hot \\
\hline $\mathrm{L}$ & $3.5 \times 10^{-8}$ & $9.0 \times 10^{-9}$ & 1.2 & $1.6 \times 10^{-5}$ & $3.0 \times 10^{-7}$ & 0.80 & hot \\
\hline M & $3.0 \times 10^{-7}$ & $8.0 \times 10^{-9}$ & 0.6 & $1.6 \times 10^{-5}$ & $3.0 \times 10^{-7}$ & 0.80 & hot \\
\hline $\mathrm{N}$ & $2.5 \times 10^{-6}$ & $3.0 \times 10^{-9}$ & 0.9 & $3.5 \times 10^{-5}$ & $1.0 \times 10^{-6}$ & 0.47 & med \\
\hline $\mathrm{O}$ & $2.5 \times 10^{-6}$ & $3.0 \times 10^{-9}$ & 0.9 & $4.0 \times 10^{-5}$ & $7.0 \times 10^{-7}$ & 0.60 & med \\
\hline $\mathrm{P}$ & $2.5 \times 10^{-6}$ & $1.4 \times 10^{-9}$ & 0.9 & $6.0 \times 10^{-5}$ & $1.5 \times 10^{-6}$ & 0.40 & med \\
\hline Q & $3.5 \times 10^{-6}$ & $4.5 \times 10^{-9}$ & 0.9 & $4.0 \times 10^{-5}$ & $1.2 \times 10^{-6}$ & 0.60 & cold \\
\hline $\mathrm{R}$ & $3.5 \times 10^{-6}$ & $2.0 \times 10^{-9}$ & 0.9 & $1.6 \times 10^{-5}$ & $3.0 \times 10^{-7}$ & 0.80 & hot \\
\hline
\end{tabular}

Composition Models

Note: All models use $\mathrm{p}_{0}=0.001 \mathrm{mbar}$ and $\mathrm{K}\left(\mathrm{p}_{0}\right)=7 \times 10^{5} \mathrm{~cm}^{2} \mathrm{~s}^{-1}$. 
and strengths from the GEISA database (Husson et al. 1991). The line profile is represented with a Voigt function. We use a collisional broadening coefficient of 0.075 and $0.11 \mathrm{~cm}^{-1} / \mathrm{bar}$ at room temperature for $\mathrm{C}_{2} \mathrm{H}_{2}$ and $\mathrm{C}_{2} \mathrm{H}_{6}$, extrapolated to other temperatures by assuming that the collision widths vary as temperature to the -0.75 power. A value of $10 \mathrm{~cm}^{-1}$ is used for the maximum extent of a spectral line. Opacity due to $\mathrm{H}_{2}-\mathrm{H}_{2}$ and $\mathrm{H}_{2}-\mathrm{He}$ collision induced transitions are computed following the formalism of Borysow et al. (1988).

The suite of models listed in Table II is designed to examine the range of possible altitude profiles for $\mathrm{C}_{2} \mathrm{H}_{2}$ and $\mathrm{C}_{2} \mathrm{H}_{6}$. For clarity, we show in Figs. 3 and 4 only those models using the best-fit temperature profile, but Table II lists models for warmer and cooler temperatures. Examination of Figs. 3 and 4 reveals that the models differ in the relative amounts of $\mathrm{C}_{2} \mathrm{H}_{2}$ and $\mathrm{C}_{2} \mathrm{H}_{6}$ at high ( $>10 \mathrm{mbar})$ and low ( $<1 \mathrm{mbar}$ ) pressure. In constructing these distributions we have been guided by previous analyses. The $\mathrm{C}_{2} \mathrm{H}_{2}$ distributions lie within the range determined from the UV studies of Wagener et al. (1985) and Bétremieux and Yelle (2000) in the 10-20 mbar region. All of the models contain far less $\mathrm{C}_{2} \mathrm{H}_{2}$ at low pressure than predicted by the photochemical models (Gladstone et al. 1996). The $\mathrm{C}_{2} \mathrm{H}_{6}$ mole fractions at 1-20 mbar agree with the results of previous IR and UV investigations (Table I) and, interestingly, the photochemical models (Gladstone et al. 1996).

Figures 5 and 6 show the spectral fits obtained with model A. Our other models produce fits of comparable quality. Model A is most consistent with prior analyses and, in fact, resembles the distributions determined by Fouchet et al. (2000), despite the different assumptions about temperature and the different latitude coverage of the observations. Figures 5 and 6 also show synthetic spectra based on Gladstone et al.'s (1996) photochemical models. Clearly, Gladstone et al.'s (1996) $\mathrm{C}_{2} \mathrm{H}_{2}$ distribution is at odds with the observations, but the $\mathrm{C}_{2} \mathrm{H}_{6}$ distribution is in excellent agreement.

We estimate the atmospheric levels probed by the emissions with calculations of the contribution function at the centers of the features, convolved to the spectral resolution of the data. For $\mathrm{C}_{2} \mathrm{H}_{2}$, this function displays interesting structure (Fig. 7). There are significant contributions at both the $10 \mathrm{mbar}$ and the 0.01 mbar levels, resulting from the pressure-broadened wings of the lines and the saturated line center, respectively. We find that if we adopt the values for the $\mathrm{C}_{2} \mathrm{H}_{2}$ mole fractions of 8.3$10 \times 10^{-7}$ and $2-4 \times 10^{-8}$ at 0.3 and 10 mbar (Fouchet et al. 2000, Wagener et al. 1985, and Bétremieux and Yelle 2000), we determine $\mathrm{a}_{2} \mathrm{H}_{2}$ mixing ratio of 1.1-4.3 $\times 10^{-6}$ at 0.01 mbar. The $\mathrm{C}_{2} \mathrm{H}_{6}$ contribution function (Fig. 7) is simpler in form than the $\mathrm{C}_{2} \mathrm{H}_{2}$ function because the lines are optically thin. There is a single peak at 5 mbar where the $\mathrm{C}_{2} \mathrm{H}_{6}$ mole fraction is 2.8-6.5 $\times 10^{-6}$. Because the contribution function for this band peaks at relatively deep pressures, we have no strong constraints on the $\mathrm{C}_{2} \mathrm{H}_{6}$ abundance at lower pressures, where the problem between observations and photochemical models of $\mathrm{C}_{2} \mathrm{H}_{2}$ was found.

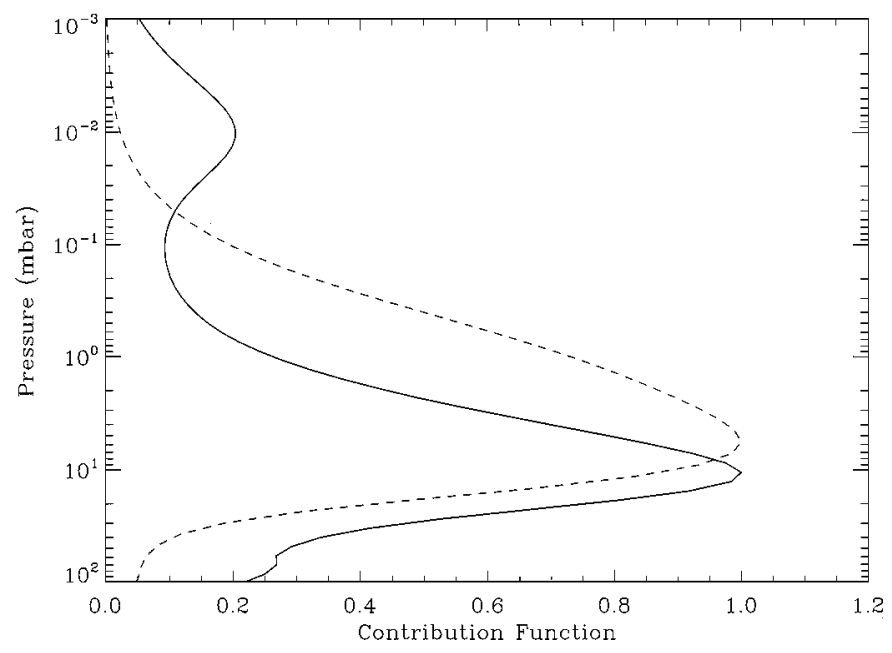

FIG . 7. The contribution functions for the emissions from $\mathrm{C}_{2} \mathrm{H}_{2}$ (solid line) and $\mathrm{C}_{2} \mathrm{H}_{6}$ (dashed line) shown in Figs. 5 and 6.

\subsection{Aerosol Distribution}

The final ingredient needed to calculate the thermal structure is the distribution and optical properties of aerosols. We utilize the results of Moreno (1996), determined from their analysis of multifilter HST images of Jupiter, as given in their Table III.

\section{ENERGY BALANCE CALCULATIONS}

Our calculations of Jupiter's thermal structure resemble those used to study Titan by Yelle (1991). Radiative processes include heating through absorption of solar energy in $\mathrm{CH}_{4}$ bands from 1.0 to $4.0 \mu \mathrm{m}$, heating by absorption of visible sunlight by aerosols, cooling by emissions from mid-IR vibrational bands of $\mathrm{CH}_{4}, \mathrm{C}_{2} \mathrm{H}_{2}$, and $\mathrm{C}_{2} \mathrm{H}_{6}$, and collisionally induced emission from $\mathrm{H}_{2}-\mathrm{H}_{2}$ and $\mathrm{H}_{2}-\mathrm{He}$. In addition to these radiative processes, the thermal structure calculations include thermal conduction. Calculations are carried out for low-latitude regions by averaging the solar heating rates over a latitude circle at $6^{\circ} \mathrm{N}$. We do not include seasonal effects, but these are small at equatorial latitudes. The calculations extend from $10^{-3}$ to 100 mbar with a resolution of 10 levels per decade of pressure.

\subsection{Solar Heating Bands}

The heating rate resulting from absorption of sunlight in the $\mathrm{CH}_{4}$ bands at near IR wavelengths is most easily calculated by using k-coefficients to represent the opacity of the atmosphere. There are a number of sources for these coefficients. Recently, Irwin et al. (1996) published k-coefficients for the $\mathrm{CH}_{4}$ bands that are based on Strong et al.'s (1993) laboratory measurements of $\mathrm{CH}_{4}$ transmission spectra. Also, Baines et al. (1993) has derived k-coefficients, over a more limited spectral region, from the laboratory measurements of Giver et al. (1990). Finally, kcoefficients may be calculated directly from a line list, such as 
HITRAN Rothman et al. 1992) or GEISA (Husson et al. 1991). We use all three of these sources in our calculations.

The good agreement between laboratory measurements and synthetic spectra for the $3.3 \mu \mathrm{m}$ band of $\mathrm{CH}_{4}$ suggests that available line lists are fairly complete (Strong et al. 1993). This is fortunate because the lowest pressure in the Strong et al. (1993) study is $0.268 \mathrm{mbar}$ and the lowest column abundance $1.723 \mathrm{~cm}$ amagat, while the peak heating in the jovian atmosphere from the 3.3 $-\mu \mathrm{m}$ band occurs at $0.001 \mathrm{mbar}$ and a column abundance of $0.06 \mathrm{~cm}$-amagat, well outside the range of the Strong et al. (1993) measurements. The Giver et al. (1990) measurements did not encompass the 3.3- $\mu \mathrm{m}$ band. We therefore use the kcoefficients derived from line-by-line calculations based on the HITRAN line list for the 3.3- $\mu \mathrm{m}$ band.

To evaluate the LBL k-coefficients, we adopt a collisional broadening parameter of $0.07 \mathrm{~cm}^{-1} \mathrm{bar}^{-1}$ at $296 \mathrm{~K}$, assumed to vary as temperature to the power of -0.75 . The maximum line extent is set at $10 \mathrm{~cm}^{-1}$. The spectrum is divided into $10 \mathrm{~cm}^{-1}$ intervals and sampled at the Doppler width of a $\mathrm{CH}_{4}$ line at the coldest temperature in the atmosphere. Ten k-coefficients are used for each interval, distributed as five Gauss-Legendre quadrature points, each between cumulative probabilities of 0 and 0.95 and between 0.95 and 1.00 . The dense sampling at large absorption coefficients allows us to accurately represent opacities in the cores of strong lines. The k-coefficients are tabulated at 61 pressures, spaced logarithmically between $10^{-3}$ mbar and $10^{3}$ mbar and at 11 temperatures spaced evenly in $1 / \mathrm{T}$ from 50 to $500 \mathrm{~K}$. Interpolation yields the k-coefficients at arbitrary pressures and temperatures.

Available line lists are not adequate for the other near IR bands of $\mathrm{CH}_{4}$ and the k-coefficients based on laboratory measurements must be used. The Irwin et al. (1996) coefficients have the advantage of wider wavelength coverage and of being based on laboratory conditions in which broadening was primarily by $\mathrm{H}_{2}$. However, the Strong et al. (1993) and Irwin et al. (1996) investigations were directed primarily toward the troposphere and, in general, concern higher pressures and temperatures than those that pertain to the jovian stratosphere. The principle advantage of the Baines et al. (1993) coefficients is their use of the Giver et al. (1990) laboratory measurements, which extend to lower temperatures than do Strong et al.'s (1993). The lowest temperature measured by Giver et al. (1990) was $112 \mathrm{~K}$, which is close to the temperature at the jovian tropopause. The lowest temperature measured by Strong et al. (1996) was $190 \mathrm{~K}$, significantly warmer than the temperature at the jovian tropopause.

Figures 8 and 9 show transmission spectra and heating rates calculated using the Irwin et al. (1996) and Baines et al. (1993) coefficients. The transmission found using the Baines et al. (1993) coefficients is significantly less than that calculated with the Irwin et al. (1996) coefficients and the heating rate is significantly higher in the 0.02-3 mbar region. However, it is not clear that the Baines et al. (1993) coefficients are more accurate than those of Irwin et al. (1993) for this region of the jovian atmosphere. There are many differences between the two studies

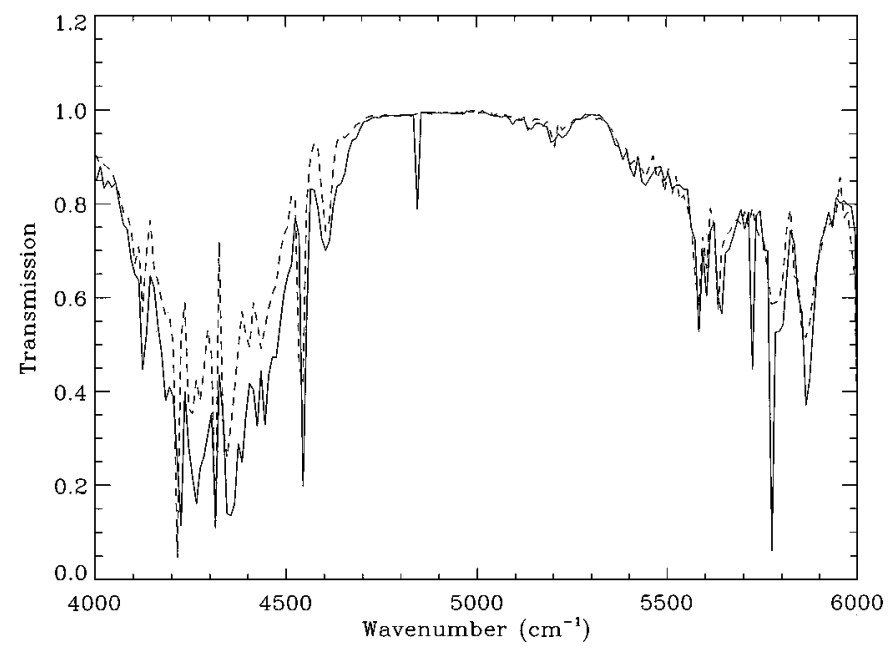

FIG. 8. Vertical transmission to 100 mbar using the Irwin et al. (1996) (solid line) and Baines et al. (1993) (dashed line) k-coefficients.

in the way that k-coefficients were determined and in the measurements themselves and, in our view, it is difficult to judge between the two. We chose the Baines et al. (1993) values because they are based on low-temperature measurements, but it is probably best to view the differences between Baines et al. (1993) and Irwin et al. (1996) as a guide to the uncertainty in the solar heating rate. The only coefficient available for the 1.1 and $1.3 \mu \mathrm{m}$ bands are those of Irwin et al. (1996), and we use these in our calculations. The choices made here are essentially the same as those of Moreno and Sedano (1997).

Information on the spectral line composition of the visible bands is lacking, thus we use the empirical absorption coefficients derived by Karkoschka (1994). The drawback to this approach is that bands are described by a single absorption

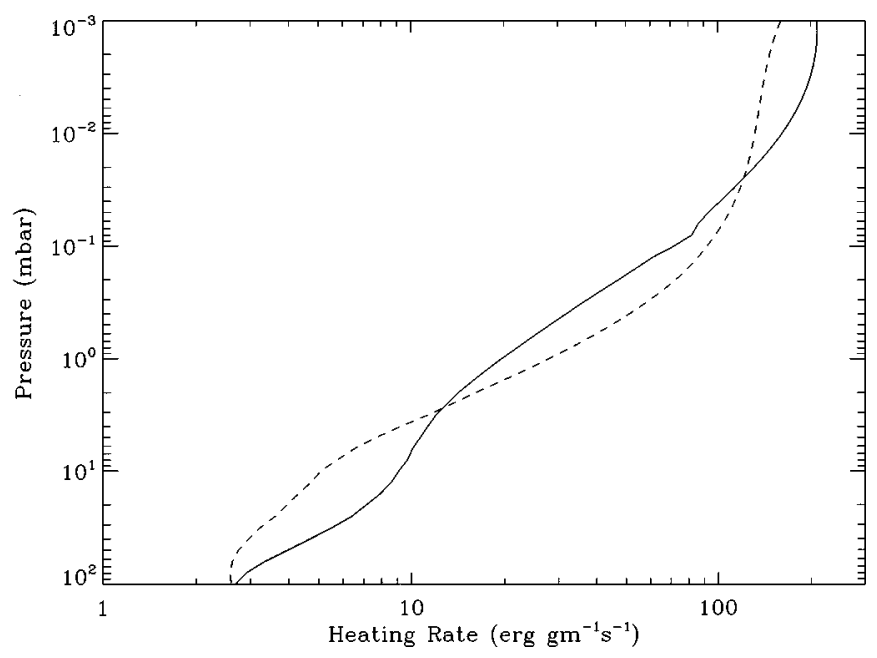

FIG. 9. Heating rates resulting from absorption in the $4000-5000 \mathrm{~cm}^{-1}$ spectral region, calculated using the Irwin et al. (1996) (solid line) and Baines et al. (1993) (dashed line) k-coefficients. 
coefficient (i.e., Beer's law) that is assumed to be independent of temperature and pressure. This is incorrect, but until our knowledge of the structure of these bands improves, no other approach is possible. The Karkoschka coefficients are determind partly through observations of Jupiter, and our calculated heating rates are therefore consistent with the observed albedo.

Aerosol absorption is modeled by assuming that the aerosols behave as Mie scatterers. Multiple scattering is included at visible wavelengths because the absorption bands are weak, and scattering by both $\mathrm{H}_{2}$ and aerosols cannot be neglected. Our radiative transfer calculations employ the DISORT routine developed by Stamnes and collaborators (Stamnes et al. 1988). Cross sections for Rayleigh-Raman scattering by $\mathrm{H}_{2}$ are obtained from Ford and Brown (1970). These calculations encompass the 0.2$1.0 \mu \mathrm{m}$ region. Absorption of sunlight at wavelengths less than $0.2 \mu \mathrm{m}$ is not treated explicitly but its effects are considered by specifying a downward conductive heat flux of $0.5 \mathrm{erg} \mathrm{cm}^{-2} \mathrm{~s}^{-1}$ at the upper boundary of the calculations (Young et al. 1997).

\subsection{Mid- and Far-IR Cooling Bands}

Cooling occurs through radiative emissions from the vibrational bands of $\mathrm{CH}_{4}, \mathrm{C}_{2} \mathrm{H}_{2}$, and $\mathrm{C}_{2} \mathrm{H}_{6}$ in the mid-IR (700$1400 \mathrm{~cm}^{-1}$ ) and collisionally induced transitions of $\mathrm{H}_{2}-\mathrm{H}_{2}, \mathrm{He}$ in the mid to far IR $\left(100-800 \mathrm{~cm}^{-1}\right)$. Our calculation follows the procedure described by Borysow et al. (1988) to model collisionally induced (CIA) transitions.

The opacities in the mid-IR vibrational bands at $1304 \mathrm{~cm}^{-1}$ $\left(\mathrm{CH}_{4}\right), 729 \mathrm{~cm}^{-1}\left(\mathrm{C}_{2} \mathrm{H}_{2}\right)$, and $822 \mathrm{~cm}^{-1}\left(\mathrm{C}_{2} \mathrm{H}_{6}\right)$ are represented with spectral mapping transformations (West et al. 1990). The absorption coefficients used to generate the spectral mapping transformations are calculated with the same techniques and line broadening parameters as for the near IR bands, but a maximum line extent of $1 \mathrm{~cm}^{-1}$ is used to reduce run time.

We find that the cooling rates in the stratosphere are sensitive to the spectrum of radiation at the lower boundary of the calculation. The usual procedure of specifying that the radiation field at the lower boundary equals the Planck function at the temperature of the lower boundary produces unacceptably large errors. This is due to the fact that the atmosphere below our lower boundary has significant temperature variations over distances of the order of a photon mean free path. Thus, we calculate the intensity field at the lower boundary by an integration through the atmosphere from 100 mbar to a depth of 10 bar.

\subsection{Thermal Conduction}

Thermal conduction becomes important at pressures less than 0.001 mbar. Thermal conduction parameters are obtained from Hanley et al. (1970). The observed temperature profile requires a downward conduction flux of $0.5 \mathrm{erg} \mathrm{cm}^{-2} \mathrm{~s}^{-1}$ at the upper boundary of our calculations. This exceeds the solar UV energy deposited in the thermosphere and may be due to viscous dissipation of gravity waves in the upper atmosphere (Young et al. 1997).

\section{RESULTS}

Heating rate calculations are shown in Fig. 10. These rates apply to all models, because they depend only on the $\mathrm{CH}_{4}$ and aerosol distributions, which are identical in all models. We subdivide the net heating rate into contributions from each of the strong $\mathrm{CH}_{4}$ bands as well as the visible region, where heating is due partly to aerosols. Because the solar flux increases with decreasing wavelength while the band strengths decrease, the $\mathrm{CH}_{4}$ bands form a progression with the longer wavelengths bands dominating at low pressures and shorter wavelength bands dominating at deeper levels. The $3.3-\mu \mathrm{m}$ band is the primary heat source at pressures less than 0.004 mbar, the $2.3-\mu \mathrm{m}$ band between 0.004 and $0.5 \mathrm{mbar}$, the $1.7-\mu \mathrm{m}$ band between 0.5 and $2 \mathrm{mbar}$, and the $1.3-\mu \mathrm{m}$ and $1.1-\mu \mathrm{m}$ bands at pressures from 2 to $25 \mathrm{mbar}$. The total heating rate is a smooth function of pressure from 0.004 to $10 \mathrm{mbar}$, varying approximately as $p^{-0.3}$.

At no level in the stratosphere is the solar heating dominated by optically thin absorption bands, which would produce a heating rate proportional to pressure. Conrath et al. (1990) argued that the lack of latitudinal gradients in the stratospheric temperature is due to the fact that the weak $\mathrm{CH}_{4}$ bands are optically thin, implying a latitude-independent heating rate. The optically thin behavior of the heating rates in Conrath et al. (1990) is a consequence of their approximate radiative transfer treatment. The small latitudinal temperature gradients on Jupiter requires a different explanation.

Absorption in the visible region contributes less than $20 \%$ of the total heating at all levels and consequently is relatively unimportant to the stratospheric thermal structure. It appears that most of this heating is due to absorption by $\mathrm{CH}_{4}$. Although, in a scattering atmosphere, we cannot separate the effects of aerosol and $\mathrm{CH}_{4}$ absorption, we find that doubling the density of aerosols increases the heating rate by less than $1 \%$. Our finding that aerosol heating is relatively unimportant agrees with the calculations of Moreno and Sedano (1997) for equatorial latitudes, but is at odds with earlier studies of the jovian stratosphere (Cess and Chen 1975, Appleby and Hogan 1984). The difference is likely due to improvements in $\mathrm{CH}_{4}$ band parameters and radiative transfer techniques. A recent study of the Uranian stratosphere also found aerosol heating to be minor (Marley and McKay 1999), though it dominates in the stratosphere of Titan (McKay et al. 1989).

The cooling rates for all composition models share some general features that we illustrate by discussing results for model A, shown in Fig. 11. $\mathrm{CH}_{4}$ dominates cooling at pressures less than $\sim 0.004$ mbar, $\mathrm{C}_{2} \mathrm{H}_{2}$ is important and sometimes dominant in the 0.01 mbar region, and $\mathrm{C}_{2} \mathrm{H}_{6}$ dominates in a broad region beginning at several hundreths of a millibar and extending to nearly 10 mbar. The relative importance of the hydrocarbon molecules is a consequence of their abundances and opacity structures. Even though it is by far the most abundant, $\mathrm{CH}_{4}$ plays a relatively minor role in the cooling rates because its spectral lines are strongly saturated, as a result of its large abundance, and this greatly reduces the cooling efficiency. $\mathrm{CH}_{4}$ is important at low 


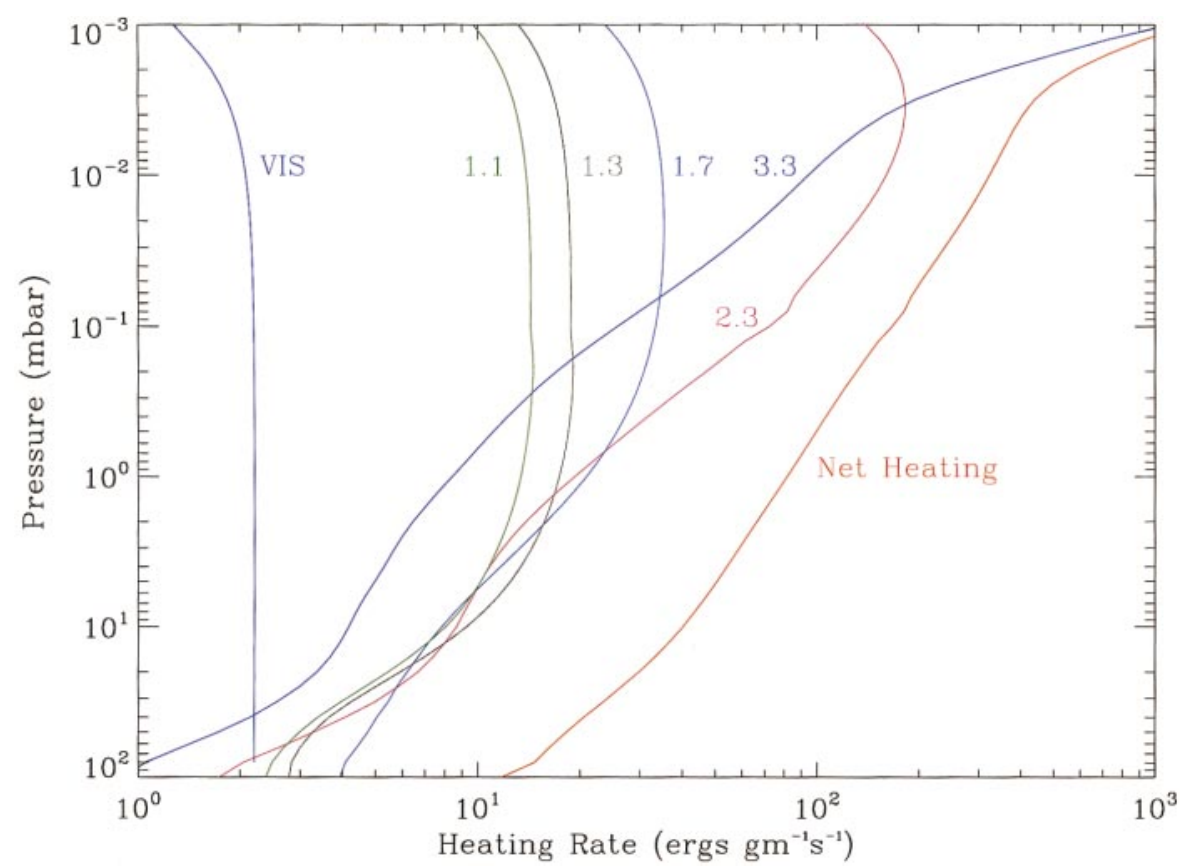

FIG. 10. Heating rates in the near IR bands of $\mathrm{CH}_{4}$ and for absorption of visible radiation by $\mathrm{CH}_{4}$ and aerosols.

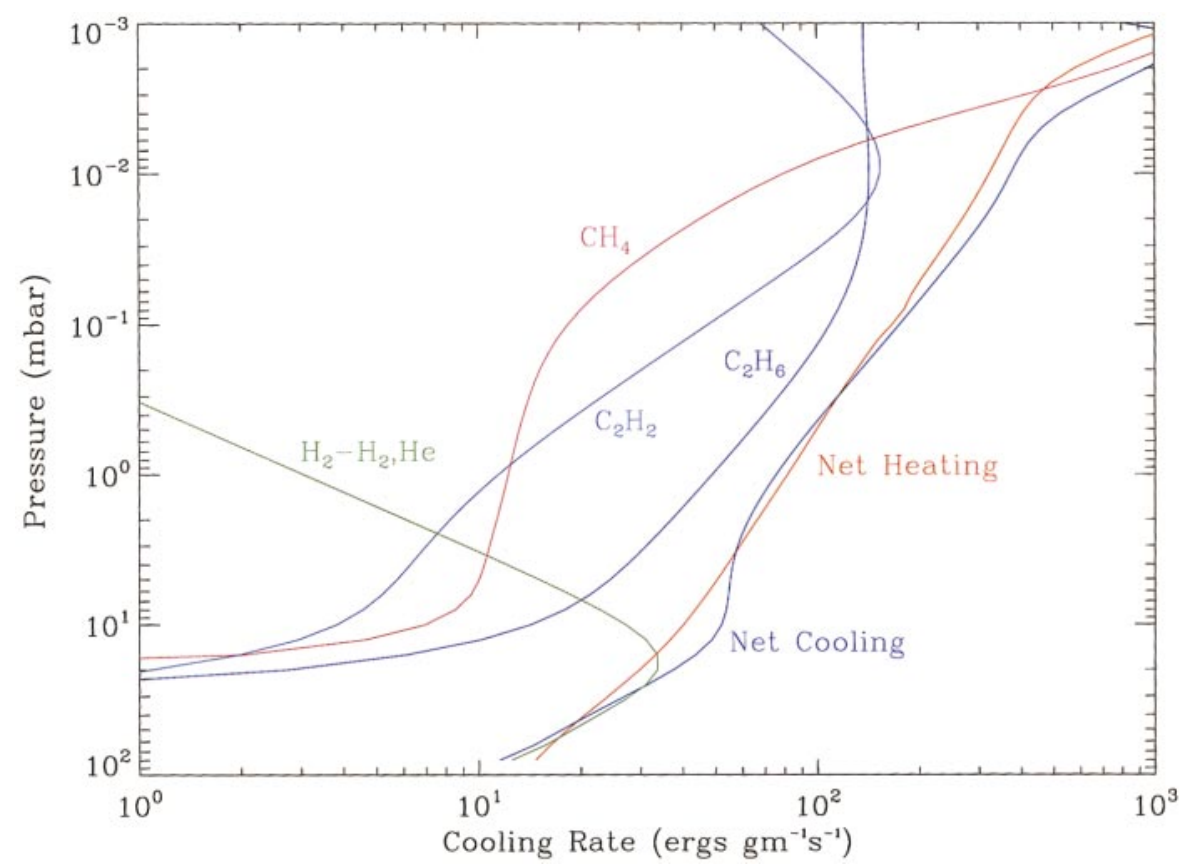

FIG. 11. The contributions to the net cooling rate for model A. $\mathrm{C}_{2} \mathrm{H}_{6}$ is the dominant coolant throughout most of the stratosphere. The net heating and cooling rates balance to good accuracy. 
pressures where some photons from the $v_{4}$ band are able to escape the atmosphere, but below 0.004 mbar the large overlying abundance of $\mathrm{CH}_{4}$ effectively traps outgoing photons. $\mathrm{CH}_{4}$ also suffers because the overlap between the $v_{4}$ band and the Planck function is weak compared with the $\mathrm{C}_{2} \mathrm{H}_{2}$ and $\mathrm{C}_{2} \mathrm{H}_{6}$ bands. Throughout most of the stratosphere, $\mathrm{C}_{2} \mathrm{H}_{2}$ and $\mathrm{C}_{2} \mathrm{H}_{6}$ are the most important coolants. The $\mathrm{C}_{2} \mathrm{H}_{2}$ cooling rate decreases with increasing pressure faster than that for $\mathrm{C}_{2} \mathrm{H}_{6}$ partly because its mole fraction decreases more quickly with pressure and partly because of differences in opacity structure. Although the $\mathrm{C}_{2} \mathrm{H}_{2}$ and $\mathrm{C}_{2} \mathrm{H}_{6}$ bands are similar in strength and fairly close in wavelength, the $\mathrm{C}_{2} \mathrm{H}_{6}$ band is diffuse with many lines over a relatively large wavelength region; the $\mathrm{C}_{2} \mathrm{H}_{2}$ band is compact with most of the band strength concentrated in a small number of lines. As a consequence, the $\mathrm{C}_{2} \mathrm{H}_{2}$ lines tend to be optically thick and are unable to cool effectively. In contrast, $\mathrm{C}_{2} \mathrm{H}_{6}$ is optically thin throughout the stratosphere.

This new result, that cooling by $\mathrm{C}_{2} \mathrm{H}_{6}$ dominates the energy balance in the stratosphere, becomes apparent when a realistic $\mathrm{C}_{2} \mathrm{H}_{6}$ altitude distribution is considered, rather than the constant mole fraction distributions assumed in earlier studies.

Cooling because of the CIA opacity of $\mathrm{H}_{2}-\mathrm{H}_{2}$ and $\mathrm{H}_{2}$-He dominates at pressures greater than $\sim 10$ mbar. Careful examination of Fig. 11 shows that the net cooling rate is actually smaller than the CIA cooling rate. This is because the net cooling rate has been defined as the sum of the contributions of CIA, $\mathrm{CH}_{4}, \mathrm{C}_{2} \mathrm{H}_{2}$, and $\mathrm{C}_{2} \mathrm{H}_{6}$. All three hydrocarbons actually heat the atmosphere near 100 mbar, because they are absorbing warmer radiation from deeper in the troposphere. This effect only appears when the radiation field at the lower boundary is accurately calculated. Once again, $\mathrm{C}_{2} \mathrm{H}_{6}$ has the largest effect and contributes a heating of $2 \mathrm{erg} \mathrm{gm}^{-1} \mathrm{~s}^{-1}$ at $100 \mathrm{mbar}$, roughly $10 \%$ of the net heating rate. Obviously, adding together the hydrocarbon and CIA terms muddles the definition of net cooling rate, but it seems to be the only sensible division.

The comparison of net heating and net cooling rates in Fig. 11 shows that the stratosphere is close to radiative equilibrium. The heating rate exceeds the cooling rate by about $5 \mathrm{erg} \mathrm{gm}^{-1} \mathrm{~s}^{-1}$ at 100 mbar and falls below the cooling rate by about 10 erg $\mathrm{gm}^{-1} \mathrm{~s}^{-1}$ at 10 mbar. Larger differences appear at pressures less than 0.003 mbar but at these levels thermal conduction and dissipation of mechanical waves are thought to be important (Young et al. 1997), and radiative equilibrium is not expected. The disagreement between the heating and cooling rate is larger if the Irwin et al. (1996) coefficients are used to calculate the heating rate in the 1.7 and $2.3 \mu \mathrm{m}$ bands; however, it would be incorrect to suggest that the net radiative imbalance in the models implies an imbalance in the atmosphere. In our view, the difference between heating rates based on Baines et al. (1993) and Irwin et al. (1996) implies that we are unable to calculate the heating rates to better than a few ergs $\mathrm{gm}^{-1} \mathrm{~s}^{-1}$. If one adopts this view, then it follows that the stratosphere is in radiative equilibrium to within a few erg $\mathrm{gm}^{-1} \mathrm{~s}^{-1}$, and there is no evidence to suggest significant departures.

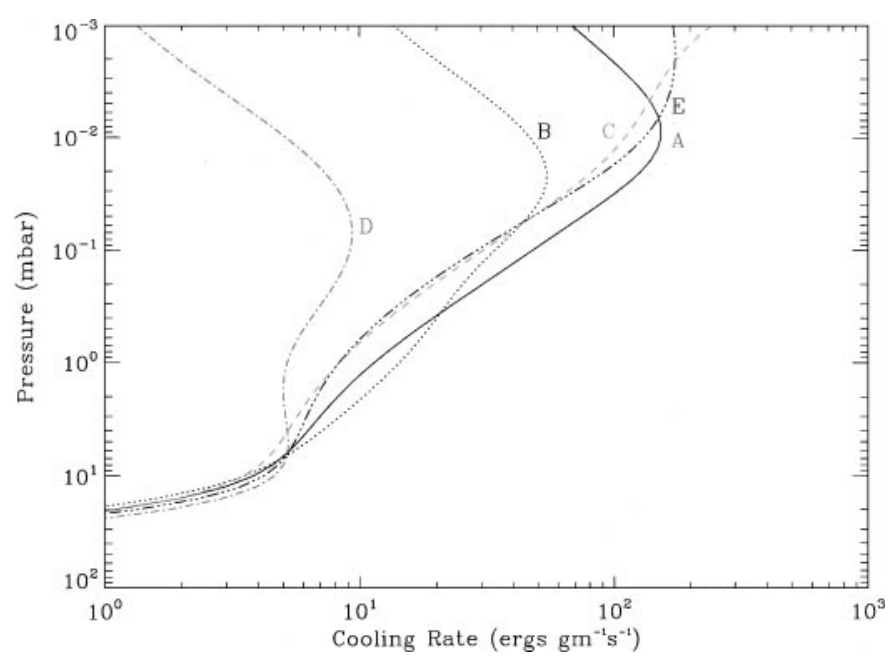

FIG . 12. Calculated cooling rates for different models of the $\mathrm{C}_{2} \mathrm{H}_{2}$ distribution described in Table II. For clarity we show only a subset of the models- the other models are very similar.

The uncertainties in the $\mathrm{C}_{2} \mathrm{H}_{2}$ and $\mathrm{C}_{2} \mathrm{H}_{6}$ altitude distributions imply relatively minor uncertainties in the radiative cooling rate. Figures 12 and 13 show calculations of the net cooling rates, based on the composition models in Table II, that illustrate the uncertainty because of $\mathrm{C}_{2} \mathrm{H}_{2}$ and $\mathrm{C}_{2} \mathrm{H}_{6}$, respectively. It is interesting that the range of possible $\mathrm{C}_{2} \mathrm{H}_{2}$ distributions produce cooling rates that are generally smaller than the nominal rate (model A) while the range of possible $\mathrm{C}_{2} \mathrm{H}_{6}$ distributions produce cooling rates that are generally larger than the nominal rate. Obviously, we could improve the match between heating and cooling rates by tweaking the $\mathrm{C}_{2} \mathrm{H}_{2}$ and $\mathrm{C}_{2} \mathrm{H}_{6}$ altitude distributions, but such an exercise would have only cosmetic value.

The disagreement between heating and cooling rates near 30 mbar is independent of composition, because $\mathrm{H}_{2}-\mathrm{H}_{2}$ CIA

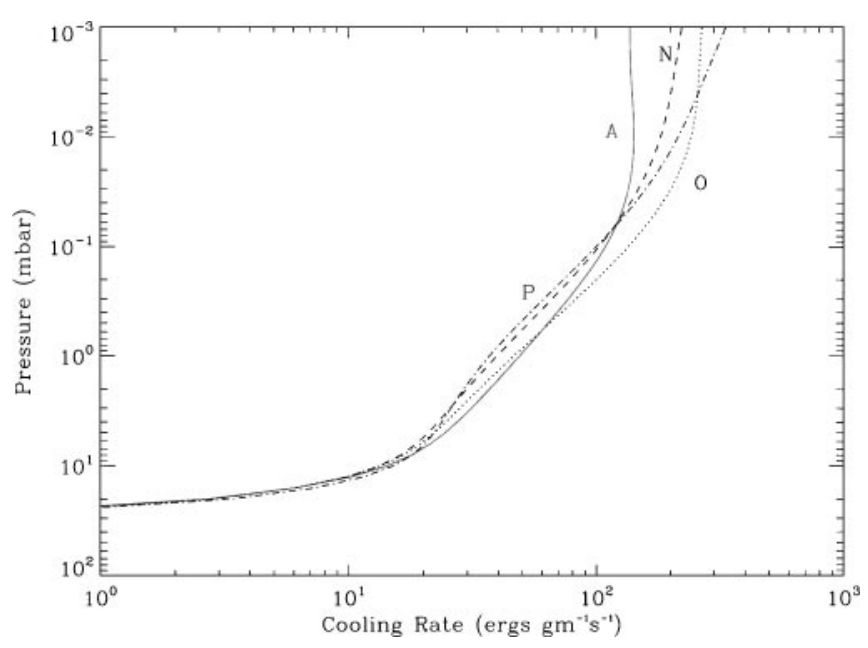

FIG . 13. Calculated cooling rates for different models of the $\mathrm{C}_{2} \mathrm{H}_{6}$ distribution described in Table II. For clarity we show only a subset of the models-the other models are very similar. 
cooling dominates in this region. Unfortunately, it is difficult to draw conclusions from this disagreement because the net heating rates are uncertain in this region by an amount comparable to the calculated imbalance. Improvements in our knowledge of the $\mathrm{CH}_{4}$ absorption coefficients are needed before this feature can be interpreted with confidence.

The radiative balance in the stratosphere can also be studied through comparison of radiative equilibrium temperatures with the measured temperatures. Figure 1 shows a radiative equilibrium temperature profile based on composition model A. This profile is calculated by adjusting the temperature in an iterative fashion until the net heating rates are $10^{-3}$ times smaller than either the heating or cooling rate alone at all levels (Yelle 1991). The calculated profile fits the ASI measurements nearly as well as the empirical models derived in Section 3.1. This reinforces the conclusion that, to within the accuracy of our calculations, the jovian equatorial stratosphere is in radiative balance.

\section{DISCUSSION}

The atmospheres in this solar system with well-developed stratospheres include the Earth, Jupiter, the other giant planets, and Titan. Neither Mars nor Venus has a warm, stable atmospheric region above the tropopause that resembles the terrestrial stratosphere. Titan's aerosol-dominated stratosphere differs significantly from the others, where gas absorption and emission dominates. Thus, we have the interesting situation in that the stratosphere of the Earth has its closest analogue not in the atmospheres of its terrestrial cousins but in the atmospheres of the giant planets.

The terrestrial stratosphere is cooled primarily by $\mathrm{CO}_{2}$ emissions and heated primarily through absorption of sunlight by $\mathrm{O}_{3}$, a product of $\mathrm{O}_{2}$ photochemistry. Thus, Earth and Jupiter share the circumstance that photochemically produced species are important in the thermal structure. Latitudinal variations in $\mathrm{O}_{3}$ play a large role in the dynamics of the terrestrial stratosphere, and it seems likely that latitudinal variations in $\mathrm{C}_{2} \mathrm{H}_{6}$ play a large role in the dynamics of the jovian stratosphere. A particularly intriguing possibility is that the intense jovian aurora, by synthesizing $\mathrm{C}_{2} \mathrm{H}_{6}$ and other thermally active hydrocarbons, could have a significant effect on the global dynamics of the stratosphere.

It follows that knowledge of the $\mathrm{C}_{2} \mathrm{H}_{2}$ and $\mathrm{C}_{2} \mathrm{H}_{6}$ chemistry is required to understand the jovian stratosphere. However, the $\mathrm{C}_{2} \mathrm{H}_{2}$ abundance determined through analysis of the Irshell observations is significantly smaller than predicted by the photochemical models of Gladstone et al. (1996). Similar conclusions regarding jovian $\mathrm{C}_{2} \mathrm{H}_{2}$ have been reached by Bézard et al. (1997b) and Fouchet et al. (2000). Our baseline model has a $\mathrm{C}_{2} \mathrm{H}_{2}$ mole fraction nearly 20 times smaller than that of Gladstone et al. (1996) at 0.01 mbar. Previous attempts to understand the low $\mathrm{C}_{2} \mathrm{H}_{2}$ abundance have postulated chemical destruc- tion of $\mathrm{C}_{2} \mathrm{H}_{2}$ by $\mathrm{H}$ atoms (Allen et al. 1992, Gladstone et al. 1996, Romani 1996. However, even the model by Romani (1996), which incorporates the most aggressive $\mathrm{C}_{2} \mathrm{H}_{2}$ destruction scheme, only decreases the $\mathrm{C}_{2} \mathrm{H}_{2}$ mole fraction by a factor of 4 from that calculated by Gladstone et al. (1996). An even more efficient $\mathrm{C}_{2} \mathrm{H}_{2}$ destruction mechanism is needed, or perhaps $\mathrm{C}_{2} \mathrm{H}_{2}$ is not produced as efficiently as currently calculated in the photochemical models.

How similar are the energetics and dynamics of the terrestrial and jovian stratospheres? This study shows that the equatorial regions on Jupiter are close to radiative equilibrium. The net radiative imbalance estimated here of $<10 \mathrm{erg} \mathrm{gm}^{-1} \mathrm{~s}^{-1}$ corresponds to a heating rate of $<10^{-3} \mathrm{~K}$ per jovian day. Heating and cooling rate in the terrestrial stratosphere are well balanced at all but polar latitudes, with net rates of $<1 \mathrm{~K}$ per earth day (Mlynczak et al. 1999a, 1999b). Though most clearly demonstrated in the Mlynczak et al. (1999a, 1999b) studies, this observational result has been known for some time. The accuracy of radiative balance was a mystery until Dunkerton (1978) explained it as a consequence of the Charney-Drazin theorem, which states that the energy transported by waves is precisely balanced by the energy carried away by the circulation established by the waves (Charney and Drazin 1961, Boyd 1976, Andrews and McIntyre 1976). This theorem applies as long as the effects of transience, nonlinearities, and dissipation are small, and this is found to be the case in the terrestrial stratosphere. This result, though profound, is primarily observational, because it is notoriously difficult to calculate the nonlinear and transient effects. Usually their presence can only be deduced from observations. Thus, we cannot say with confidence whether the radiative dominance of the terrestrial stratosphere is a general result, linked to the Charney-Drazin theorem, or peculiar to the Earth.

Observations of several planetary stratosphere are required to determine if radiative dominance is a general rule. The Friedson et al. (1999) study finds that aerosols are transported primarily by eddies associated with a wave-driven circulation, implying that the jovian stratosphere differs fundamentally from that of the Earth. However, it would be premature to adopt this as a firm conclusion until latitudinal variations in $\mathrm{C}_{2} \mathrm{H}_{2}$ and $\mathrm{C}_{2} \mathrm{H}_{6}$ are included in dynamical models of the jovian stratosphere.

\section{CONCLUSIONS}

Our conclusions can be summarized as follows:

1. $\mathrm{C}_{2} \mathrm{H}_{6}$ is the primary coolant in the equatorial jovian stratosphere in the 0.05-10 mbar pressure region. This result differs from previous analyses and is a consequence of considering realistic density distributions for $\mathrm{C}_{2} \mathrm{H}_{6}$. It is interesting that the energetics of the jovian stratosphere are dominated by a photochemically produced molecule.

2. Latitudinal variations in the abundance of $\mathrm{C}_{2} \mathrm{H}_{2}$ and $\mathrm{C}_{2} \mathrm{H}_{6}$ between 0.004 and 10 mbar must be taken into account in 
dynamical models. As the primary thermally active species, they could play a large role in forcing stratospheric dynamics.

3 . The stratosphere is close to radiative balance in the $0.03-$ 100 mbar region. The net radiative heating rate is of order or smaller than the uncertainties in heating rate calculations.

4. Significant uncertainties still exist in the absorption coefficients for the near IR bands of $\mathrm{CH}_{4}$. Better data are needed to improve our ability to accurately calculate solar heating rates.

5. The mole fraction of $\mathrm{C}_{2} \mathrm{H}_{2}$ in the 0.004-0.02 mbar region and $\mathrm{C}_{2} \mathrm{H}_{6}$ in the $0.4-10$ mbar region are $1.1-4.3 \times 10^{-6}$ and 2.8$6.5 \times 10^{-6}$, respectively. This $\mathrm{C}_{2} \mathrm{H}_{2}$ abundance is much less than predicted by photochemical models; the $\mathrm{C}_{2} \mathrm{H}_{6}$ abundance is in good agreement.

These conclusions imply that the photochemistry, radiative balance, and dynamics of the jovian stratosphere are strongly coupled and must be treated in a self-consistent manner.

\section{APPE NDIX: TE MPERATURE -INDE PE NDENT FORMULATION OF THE DIFFUSION EQUATION}

The usual form of the diffusion equation is

$$
\Phi_{i}=-D\left(\frac{d N_{i}}{d z}+\frac{N_{i}}{H_{i}}+\frac{N_{i}}{T} \frac{d T}{d z}\right)-K\left(\frac{d N_{i}}{d z}+\frac{N_{i}}{H_{a}}+\frac{N_{i}}{T} \frac{d T}{d z}\right) .
$$

Changing variables from number density $N_{i}$ to mole fraction $f_{i}$ and from altitude $z$ to $Z$, Where $Z=-\log \left(p / p_{0}\right)$ and $p_{0}$ is a reference pressure, we have

$$
-\frac{\Phi_{i} H_{a}}{(D+K) N_{a}}=\frac{d f_{i}}{d Z}+\frac{\left(m_{i} / m_{a}-1\right) D}{D+K} f_{i}
$$

where $N_{a}$ is the total number density and $H_{a}$ the pressure scale height. We assume that the molecular diffusion coefficient varies as $D=g(T) p_{0} / p$ and the eddy diffusion coefficient as $K=g(T)\left(p_{0} / p\right)^{\gamma}$ so that the ratio $D / K$ depends only on pressure: $D / K=r\left(p_{0} / p\right)^{1-\gamma}$ where $r$ is a constant and $p_{0}$ a reference pressure. The function $g(T)$ is arbitrary, but we assume that $K$ and $D$ have this same temperature dependence. We now restrict out attention to cases where the flux is zero. In this case, Eq. (A2) has a simple analytic solution with no explicit temperature dependence,

$$
f(p)=f(\infty)\left(1+r\left(p_{0} / p\right)^{1-\gamma}\right)^{\frac{1-m_{i} / m_{a}}{1-\gamma}} .
$$

The assumptions leading to this result are not restrictive. Because the eddy diffusion coefficient is often treated as a parameter to be determined by fitting observations, nothing is lost by assuming a specific temperature dependence. There is usually sufficient freedom with the pressure dependence to fit any observations, but if the two parameter model for $K$ adopted here is found to be inadequate, more complex profiles can be constructed by joining solutions for different regions in a piecewise continuous fashion. The lack of an explicit temperature dependence means that A3 can be used in nonisothermal atmospheres and makes this approach particularly useful for thermal structure calculations.

\section{ACK NOW LED GMENTS}

This work has been supported by the NASA Planetary Atmospheres Program through grant NAG5-4426, the NSF Young Investigator program, and The Research Corporation. We thank J ulie Moses for discussions on photochemistry and helpful comments on an earlier draft, Bruno Bézard for discussions on the Irshell observations, and Fernado Moreno for discussions on heating rates.

\section{REFERENCES}

Allen, M., Y. L. Yung, and G. R. Gladstone 1992. The relative abundance of ethane to acetylene in the jovian stratosphere. Icarus 100, 527533.

Andrews, D. G., and M. E. McIntyre 1976. Planetary waves in horizontal and vertical shear: The generalized Eliassen-Palm relation and the mean zonal acceleration. J. Atmos. Sci. 33, 2031-2048.

Appleby, J. F. 1990. $\mathrm{CH}_{4}$ nonlocal thermodynamic equilibrium in the atmospheres of the giant planets. Icarus 85, 355-379.

Appleby, J. F., and J. S. Hogan 1984. Radiative-convective equilibrium models of Jupiter and Saturn. Icarus 59, 336-366.

Axel, L. 1972. Inhomogeneous models of the atmosphere of Jupiter. Astrophys. J. 175, 451.

Baines, K. H., R. A. West, L. P. Giver, and F. Moreno 1993. Quasi-random narrow-band model fits to near-infrared low-temperature laboratory methane spectra and derived exponential-sum absorption coefficients. J. Geophys. Res. 98, 5517-5529.

Bétremieux, Y., and R. V. Yelle 1999. HST detection of $\mathrm{H}_{2}$ Raman scattering in the jovian atmosphere. Icarus 142, 324-341.

Bétremieux, Y., and R. V. Yelle 2000. HST observation of the atmospheric structure of Jupiter's equatorial region: evidence for lightning-induced chemistry. Icarus, submitted.

Bézard, B., C. A. Griffith, and D. Kelly 1997a. Search for $\mathrm{NH}_{3}$ in Jupiter's stratosphere ten months after SL9 collisions. Icarus 125, 331-339.

Bézard, B., C. A. Griffith, D. M. Kelly, J. H. Lacy, T. Greathouse, and G. Orton 1997b. Thermal infrared imaging spectroscopy of Shoemaker-Levy 9 impact sites: temperature and $\mathrm{HCN}$ retrievals. Icarus 125, 94-120.

Borysow, J., L. Frommhold, and G. Birnbaum 1988. Collision-induced rototranslational absorption spectra of $\mathrm{H}_{2}-\mathrm{He}$ pairs at temperatures from 40 to 3000 K. Astrophys. J. 326, 509-515.

Boyd, J. 1976. The non-interaction of waves with the zonally-averaged flow on a spherical earth and the interrelationships of eddy fluxes of energy, heat, and momentum. J. Atmos. Sci. 33, 2285-2291.

Cess, R. D., and S. C. Chen 1975. The influence of ethane and acetylene upon the thermal structure of the jovian atmosphere. Icarus 26, 444-450.

Cess, R. D., and S. Khetan 1973. Radiative transfer within the atmospheres of the major planets. J. Quant. Spectrosc. Radiat. Trans. 13, 995-1009.

Chamberlain, J. W., and D. M. Hunten 1987. Theory of Planetary Atmospheres. Academic Press, San Diego, CA.

Charney, J. G., and P. G. Drazin 1961. Propagation of planetary scale disturbances from the lower into the upper atmosphere. J. Geophys. Res. 66, 83109.

Clarke, J. T., H. W. Moos, and P. D. Feldman 1982. The far ultraviolet spectra and geometric albedos of Jupiter and Saturn. Astrophys. J. 255, 806818.

Combes, M., Th. Encrenaz, L. Vapillion, Y. Zéau, and C. Lesqueren 1974. Confirmation of the identification of $\mathrm{C}_{2} \mathrm{H}_{2}$ and $\mathrm{C}_{2} \mathrm{H}_{6}$ in the jovian atmosphere. Astron. Astrophys. 34, 33-35.

Conrath, B. J., P. J. Gierasch, and S. S. Leroy 1990. Temperature and circulation in the stratosphere of the outer planets. Icarus 83, 255-281.

Dunkerton, T. 1978. On the mean meridional mass motions of the stratosphere and mesosphere. J. Atmos. Sci. 35, 2325-2333.

Edgington, S. G., S. K. Atraya, L. M. Trafton, J. J. Coldwell, R. F. Beebe, A. A. Simon, R. A. West, and C. Barnet 1998. On the latitude variation of ammonia, acetylene, and phosphine altitude profiles on Jupiter from HST faint object spectrograph observations, Icarus, 133, 192-209. 
Encrenaz, Th., M. Combes, and Y. Zéau 1978. The spectrum of Jupiter between 10 and $13 \mu$ : An estimate of the jovian, 15N/14N ratio. Astron. Astrophys. 70, 29-36.

Ford, A. L., and J. C. Browne 1973. Rayleigh and Raman cross sections for the hydrogen molecule. Atomic Data 5, 305-313.

Fouchet, T., E. Lellouch, B. Bézard, H. Feuchtgruber, P. Drossart, and T. Encrenaz 2000. Jupiter's hydrocarbons observed with ISO-SWS: vertical profiles of $\mathrm{C}_{2} \mathrm{H}_{6}$ and $\mathrm{C}_{2} \mathrm{H}_{2}$, detection of $\mathrm{CH}_{3} \mathrm{C}_{2} \mathrm{H}$. Astron. Astrophys. 35, 113-117.

Friedson, A. J. 1999. New observations and modelling of a QBO-like oscillation in Jupiter's stratosphere. Icarus 137, 34-55.

Friedson, A. J., R. A. West, A. K. Hronek, N. A. Larsen, and N. Dalal 1999. Transport and mixing in Jupiter's stratosphere inferred from comet SL-9 dust migration. Icarus 138, 141-156.

Gillet, F. C., F. J. Low, and W. A. Stein 1969. The 2.8-14 $\mu \mathrm{m}$ spectrum of Jupiter. Astrophys. J. 157, 925.

Giver, L. P., D. C. Benner, M. G. Tomasko, U. Fink, and D. Kerola 1990. Gaussian quadrature exponential sum modelling of near-infrared methane laboratory spectra obtained at temperatures from 106 to 297 K, NASA Conf. Publ., CP3077, 147-156.

Gladstone G. R., and Y. L. Yung 1983. An analysis of the reflection spectrum of Jupiter from $1500 \AA$ to $1740 \AA$ A Astrophys. J. 266, 415-424.

Gladstone, G. R., M. Allen, and Y. L. Yung 1996. Hydrocarbon photochemistry in the upper atmosphere of Jupiter. Icarus 119, 1-52.

Griffith, C. A., B. Bézard, T. K. Greathouse, D. M. Kelly, J. H. Lacy, and K. S. Noll 1997. Thermal infrared imaging spectroscopy of Shoemaker-Levy 9 impact sites: Spatial and vertical distributions of $\mathrm{NH}_{3}, \mathrm{C}_{2} \mathrm{H}_{4}$, and $10 \mu \mathrm{m}$ dust emission. Icarus 128, 275-293.

Hanley, H. M. J., R. D. McCarthy, and H. Intermann 1970. The viscosity and thermal conductivity of dilute hydrogen from 150 to 5000 K. J. Res. Natl. Bur. Stand. U. S. Sect. A. 74, 331-353.

Hubbard, W. B., R. E. Nather, D. S. Evans, F. G. Tull, D. C. Wells, G. W. Van Citters, B. Warner, and P. Vanden Bout 1972. The occultation of $\beta$ Scorpii by Jupiter and Io. I, Jupiter. Astron. J. 77, 41-59.

Hubbard, W. B., V. Hammerle, C. C. Porco, G. H. Rieke, and M. J. Rieke 1995. The occultation of Jupiter by SAO 78505. Icarus 113, 103-109.

Husson, N., B. Bonnet, N. A. Scott, and A. Chédin 1991. The GEISA Data Bank 1991 Version. Internal note L.M.D. 163, Laboratoire de Métorologie Dynamique, Plaiseau, France.

Irwin, P. G. J., S. B. Calcutt, F. W. Taylor, and A. L. Weir 1996. Calculated k distribution coefficients for hydrogen- and self-broadened methane in the range $2000-9500 \mathrm{~cm}^{-1}$ from exponential sum fitting to band modelled spectra. J. Geophys. Res. E. 101, 26137-26154.

Karkoschka, E. 1994. Spectrophotometry of the jovian planets and Titan at 300- to 1000-nm wavelength: The methane spectrum. Icarus 111, 174192.

Kostiuk, T., F. Espenak, M. J. Mumma, D. Deming, and D. Zipoy 1987. Variability of ethane on Jupiter. Icarus 72, 394-410.

Lacy, J. H., J. M. Achterman, D. E. Bruce, D. F. Lester, J. F. Arens, M. C. Peck, and S. D. Gaalema 1989. Irshell: A mid-infrared cryogenic echelle spectrograph. Publ. Astron. Soc. Pacific. 101, 1166-1175.

Leovy, C. B., A. J. Friedson, and G. S. Orton 1991. The quasiquadrennial oscillation of Jupiter's equatorial stratosphere. Nature 354, 380-382.

Lindal, G. F., G. E. Wood, G. S. Levy, J. D. Anderson, D. N. Sweetnam, H. B. Hotz, B. J. Buckles, D. P. Holmes, P. E. Doms, V. R. Eshleman, G. L. Tyler, and T. A. Croft 1981. The atmosphere of Jupiter: An analysis of the Voyager radio occultation measurements. J. Geophys. Res. 86, 87218727.

Marley, M. S., and C. P. McKay 1999. Thermal structure of Uranus' atmosphere. Icarus 138, 268-286.
Mason, E. A., and T. R. Marrero 1970. The diffusion of atoms and molecules. In Advances in Atomic and Molecular Physics (D. R. Bates and I. Estermann, Eds.), Academic Press, New York.

McGrath, M. A., G. E. Ballester, and H. W. Moos 1990. Jovian Hz day glow emission, J. Geophys. Res. 95, 10365-10373.

McKay, C. P., J. B. Pollack, and R. Courtin 1989. The thermal structure of Titan's atmosphere. Icarus 80, 23-53.

Moreno, F. 1996. The structure of the stratospheric aerosol layer in the equatorial and South Polar region of Jupiter. Icarus 124, 632-644.

Moreno, F., and J. Sedano 1997. Radiative balance and dynamics in the stratosphere of Jupiter: Results from a latitude-dependent aerosol heating model. Icarus 130, 36-48.

Morrissey, P. F., P. D. Feldman, M. A. McGrath, B. C. Wolven, and H. W. Moos 1995. The ultraviolet reflectivity of Jupiter at 3, $5 \AA$ resolution from ASTRO-1 and ASTRO-2, Ap. J. 454, L65-L68.

Mlynczak, M. G., C. J. Mertens, R. R. Garcia, and R. W. Portmann 1999a. A detailed evaluation of the stratospheric heat budget 1 . Radiation transfer. J. Geophys. Res. 104, 6021-6038.

Mlynczak, M. G., C. J. Mertens, R. R. Garcia, and R. W. Portmann 1999b. A detailed evaluation of the stratospheric heat budget 2 . Global radiation balance and diabatic circulations. J. Geophys. Res. 104, 6039-6066.

Neimann, H. B., S. K. Atreya, G. R. Carignan, T. M. Donahue, J. A. Haberman, D. N. Harpold, R. E. Hartle, D. M. Hunten, W. T. Kasprzak, P. R. Mahaffy, T. C. Owen, N. W. Spencer, and S. H. Way 1996. The Galileo probe mass spectrometer: Composition of Jupiter's atmosphere. Science 272, 846849.

Noll, K. R. F. Knacke, A. T. Tokunaga, J. H. Lacy, S. Beck, and E. Serabyn 1986. The abundance of ethane and acetylene in the atmospheres of Jupiter and Saturn. Icarus 65, 257-263.

Orton, G. S., and G. Aumman 1977. The abundance of acetylene in the atmosphere of Jupiter. Icarus 32, 431-436.

Orton, G. S., A. J. Freidson, J. Caldwell, H. B. Hammel, K. H. Baines, J. T. Bergstralh, T. Z. Martin, M. E. Malcom, R. A. West, W. F. Golisch, D. M. Greip, C. D. Kaminski, A. T. Tokunaga, R. Baron, and M. Shure, 1991. Thermal maps of Jupier: spatial organization and time dependence of stratospheric temperatures, 1980 to 1990 . Science 252, 537-542.

Ragent, B., D. S. Colburn, K. A. Rages, T. C. D. Knight, P. Avrin, G. S. Orton, P. Yanamandra-Fisher, and G. W. Grams 1998. The clouds of Jupiter: Results of the Galileo Jupiter mission probe nephelometer experiment. J. Geophys. Res. 103, 22891-22910.

Ridgway, S. T. 1974. Jupiter: Identification of ethane and acetylene. Astrophys. J. 187, L41-L43.

Romani, P. N. 1996. Recent rate constant and product measurements of the reactions of $\mathrm{C}_{2} \mathrm{H}_{3}+\mathrm{H}_{2}$ and $\mathrm{C}_{2} \mathrm{H}_{3}+\mathrm{H}$. Importance for photochemical modeling of hydrocarbons on Jupiter. Icarus 122, 233-241.

Rothman, L. S., R. R. Gamache, R. H. Tipping, C. P. Rinsland, M. A. H. Smith, D. C. Benner, V. Malathy Devi, J. M. Flaud, C. Camy-peyret, A. Perrin, A. Goldman, S. T. Massie, L. R. Brown, and R. A. Toth 1992. The Hitran database: Editions of 1991 and 1992. J. Quant. Spectrosc. Radiat. Trans. 48, 469-507.

Sada, P. V., G. L. Bjorker, D. E. Jennings, G. H. McCabe, and P. N. Romani 1998. Observations of $\mathrm{CH}_{4}, \mathrm{C}_{2} \mathrm{H}_{6}$, and $\mathrm{C}_{2} \mathrm{H}_{2}$ in the stratosphere of Jupiter. Icarus 136, 192-201.

Sieff, A., D. B. Kirk, T. C. D. Knight, L. A. Young, F. S. Milos, E. Venkatapathy, J. D. Mihalov, R. C. Blanchard, R. E. Young, and G. Schubert 1997. Thermal structure of Jupiter's upper atmosphere derived from the Galileo probe. Science 276, 402-405.

Sieff, A., D. B. Kirk, T. C. D. Night, R. E. Young, J. D. Mihalov, L. A. Young, F. S. Milos, G. Schubert, R. C. Blanchard, and D. Atkinson 1998. Thermal structure of Jupiter's atmosphere in the North Equatorial Belt, near the edge of a $5 \mu \mathrm{m}$ hot spot. J. Geophys. Res. 103, 22857-22890. 
Stamnes, K., S. Tsay, W. Wiscombe, and K. Jayweera 1988. Numerically stable algorithm for discrete-ordinate-method radiative transfer in multiple scattering and emitting layered media. Appl. Opt. 27, 2502-2509.

Strong, K., F. W. Taylor, S. B. Calcutt, J. J. Remedios, and J. Ballard 1993. Spectral parameters of self- and hydrogen-broadened methane from 2000 to $9500 \mathrm{~cm}^{-1}$ for remote sounding of the atmosphere of Jupiter, J. Quant. Spectrosc. Radiat. Trans. 50, 309-325.

Tokunaga, A., R. F. Knacke, and T. Owen 1976. Ethane and acetylene abundances in the jovian atmosphere. Astrophys. J. 209, 294301.

Wagener, R., J. Caldwell, T. Owen, and S.-J. Kim, Th. Encrenaz, and M. Combes 1985. The jovian stratosphere in the ultraviolet. Icarus 63, 222236.

Wallace, L., M. Prather, and M. J. S. Belton 1974. The thermal structure of the atmosphere of Jupiter, Astrophys. J. 193, 481-493.

West, R. A., L. Chen, and D. Crisp 1990. Mapping transformations for broad band atmospheric radiation calculations. J. Quant. Spectrosc. Trans. 43, 191199.

West, R. A., A. J. Friedson, and J. F. Appleby 1992. Jovian large-scale stratospheric circulation. Icarus 100, 245-259.

Ververka, J., L. H. Wasserman, J. Elliot, C. Sagan, and W. Liller 1974. The occultation of beta Scorpii by Jupiter I. The structure of the jovian upper atmosphere. Astrophys. J. 79, 73.

Yelle, R. V. 1991. Non-LTE models for Titan's upper atmosphere. Astrophys. J. 101, 100-121.

Yelle, R. V., L. A. Young, R. J. Vervack Jr., R. Young, L. Pfister, and B. R. Sandel 1996. Structure of Jupiter's upper atmosphere: Predictions for Galileo. J. Geophys. Res. 101, 2149-2161.

Young, R. E. 1998. The Galileo Probe mission to Jupiter: Science overview. J. Geophys. Res. 103, 22775-22790.

Young, L. A., R. V. Yelle, R. E. Young, A. Sieff, and D. Kirk 1997. Gravity, waves in Jupiter's thermosphere. Science 276, 108-111. 